\title{
AUTONOMY AND INFORMED CONSENT
}

\author{
Eileen F. Baker
}

\section{A Dissertation}

Submitted to the Graduate College of Bowling Green State University in partial fulfillment of the requirements for the degree of

\section{DOCTOR OF PHILOSOPHY}

May 2017

Committee:

Michael E. Weber Advisor

Juan L. Bouzat

Graduate Faculty Representative

Michael P. Bradie

Dale S. Klopfer

Sara Worley 


\begin{abstract}
Michael E. Weber, Advisor

The process of obtaining informed consent is designed to operationalize respect for autonomy. Informed consent requires that the agent have capacity for decision-making, that the agent be informed, and that the agent's decision be voluntary. Under most circumstances, patients are presumed competent, and the onus is upon the practitioner to prove otherwise. I argue that informed consent, in its current practice, fails to ensure respect for autonomy.

Complacency on the part of both patients and practitioners leads to four flaws that have the potential either to undermine patient autonomy or to presume competence where it is absent. Practitioners must do their due diligence in assessing patients for competence, above and beyond the minimum required in the consent document. I call this process Rigorous Informed Consent. I propose two solutions for improving the informed consent process. The first utilizes "informed consent specialists" to ensure that patients are properly informed. The second implements "informed consent coding" to define the level of capacity required for a given clinical situation, on a numerical scale.
\end{abstract}

Next, I analyze four domains of influence upon authenticity and describe potential "red flags" for authenticity issues. I present my own formulation of what elements are required for autonomous agency and introduce the concepts of Substantial Autonomy and Threshold Competence. "Full autonomy" or "ideal autonomy" is not always possible, nor is it always necessary to attain. 
The "exceptional cases," are when agents are assumed to be incompetent, simply because they are refusing the treatment that is recommended by their practitioners. I cite studies that show that that suicide is no more prevalent in the terminally ill than in the general population, that depressed patients maintain both capacity and appreciation of their situation, that preferences for the end of life amongst depressed patients are similar to those without depression, and that patient's preferences are stable over time, even after treatment for depression. I explain how Threshold Competence can be applied to depressed patients and argue that mild to moderate depression does not significantly alter patients' preferences, so the wishes they express should be taken as reliable and authentic. 
For Gary, with gratitude for his continued support of "shark research." 


\section{ACKNOWLEDGMENTS}

First, I am grateful to the faculty, staff and students of the Department of Philosophy at Bowling Green State University, for allowing me to matriculate and rub elbows with full-fledged philosophers. Earning my degree would not have been possible without the flexibility to enroll in the program part-time, while still maintaining my "real job" as an emergency physician in the local community.

I would like to thank Dr. Michael E. Weber for agreeing to serve as Advisor to my dissertation committee. Dr. Weber sets a very high bar, and the formulation and evolution of my work reflect this. Additionally, on a personal level, it has been a pleasure not only to discuss the philosophical matters at hand, but to engage in political dialogue with a like-minded individual.

Next, I have been pleased to enjoy the philosophical insight that Dr. Sara Worley has provided, both in class and with this project. I admire her intelligence and good humor. She even laughs at my jokes. Thank you.

I thank Dr. Michael P. Bradie, now Professor Emeritus, for agreeing to serve on my committee. His brilliance is unmatched, and I am honored that he would spend part of the best years of his life (his retirement) with me.

I am fortunate to have Dr. Juan L. Bouzat serving as Graduate Faculty Representative, sharing his intuitions from the perspective of the life sciences. The biological sciences were my first love, prompting me to set sights upon a career in medicine, from a young age. The Philosophy of Evolution course, co-instructed with Dr. Bradie, brought the worlds of science and philosophy together and challenged students from both areas of interest. 
Without Dr. Dale S. Klopfer, my Preliminary Exam would not have been possible, as he stepped in, literally at the last minute, to attend. Thank you for the sacrifice of your time, in my interest.

I am grateful to Ms. Kara Lee (Kari) Dyer not only for providing feedback on many early drafts of my dissertation, but for her encouragement and friendship.

I thank Dr. Catherine Marco, my long-term colleague in emergency medicine, for objectively reviewing portions of my work to ensure their scientific rigor.

It was my good fortune to join the ranks of Bowling Green students to bask in the presence of Dr. Raymond G. Frey. With a wink, he could convince you not only that his skills on the tennis court were superior to those of Roger Federer, but that you truly would be better off to relinquish your autonomy to him. He remarked that while he had the freedom, as a learned philosopher, to speak of killing people, I, as a physician, should take care to speak and do otherwise. I so would have enjoyed his participation on my Dissertation Committee, and he is dearly missed.

While I am twice the age of most graduate students, this does not mean that I don't need a "mom" in my Philosophy Department. Thank you, Ms. Margaret (Margy) DeLuca for ensuring that all fees were paid, all deadlines were met, and all important events were celebrated. Ms. DeLuca is an invaluable gem, to whom all in the Department are indebted.

Finally, I am grateful to my family: to my parents, for their eternal pride in my accomplishments, great and small; and to my husband, Gary Farson, who reminds me that all accomplishments are small, cosmologically speaking. 
TABLE OF CONTENTS

Page

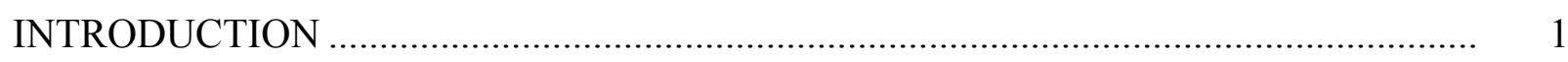

CHAPTER 1: PROBLEMS WITH INFORMED CONSENT ………………………........... 9

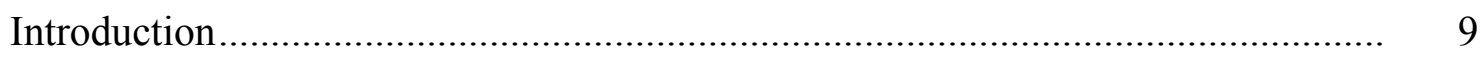

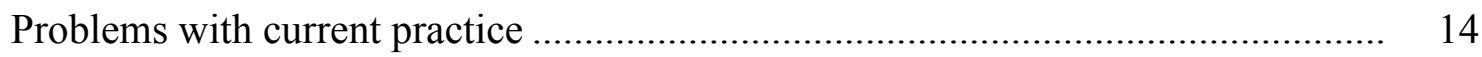

The "Expedience Problem".......................................................................... 15

The "Least Agreement Problem"............................................................. 17

The "Defeater Problem" ............................................................................... 19

The "False Consent Problem"................................................................... 19

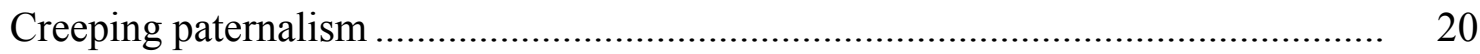

A brief discussion of paternalism .................................................................... 21

"Best for" terminology and paternalistic language ................................................. 23

Potential solutions: the importance of flexibility and the need for due diligence .... 25

Potential solutions: informed consent specialists .................................................. 29

Potential solutions: informed consent coding ...................................................... 31

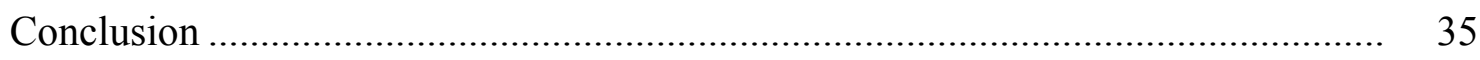

CHAPTER 2: THE IMPORTANCE OF AUTHENTICITY AND VALUES ...................... 37

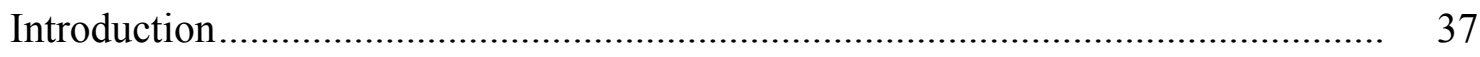

Authenticity and the self ......................................................................... 38

Questioning a patient's choice—the Authenticity vs. Agency Question................... 43

External features and pressures.................................................................... 47

Authenticity, voluntarism and values ………………..................................... 48 


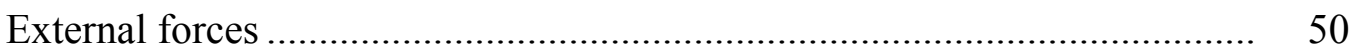

Developmental factors ................................................................... 51

Illness-related considerations ............................................................... 51

Psychological, cultural and religious influences.......................................... 52

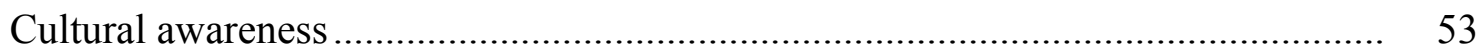

Red flags for authenticity and consent issues and their solutions............................ 55

Signs of pressure or influence................................................................. 55

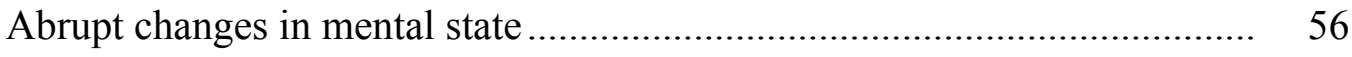

Refusal of treatment ........................................................................... 56

Consenting to treatment that is especially invasive or risky ........................ 57

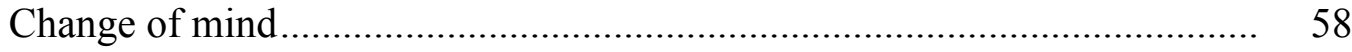

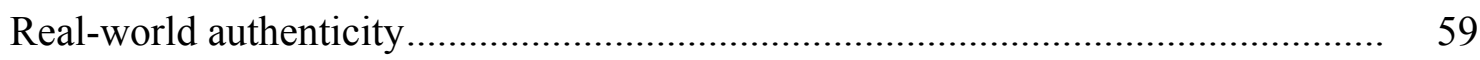

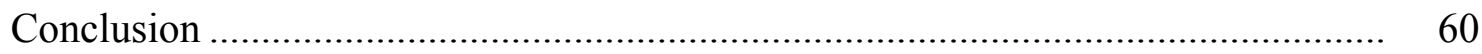

CHAPTER 3: SUBSTANTIAL AUTONOMY AND THRESHOLD COMPETENCE ..... 62

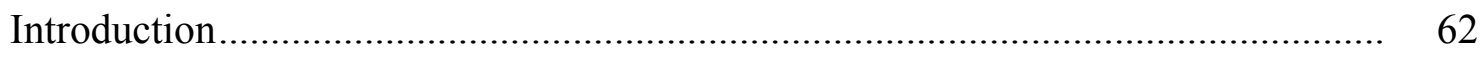

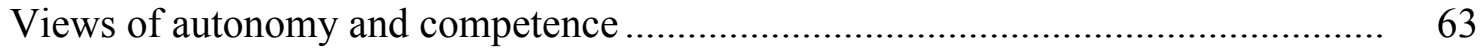

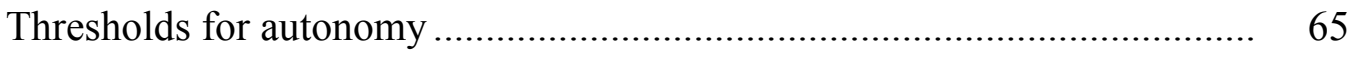

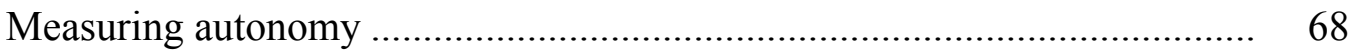

Risk, consequences, and complexity ………………………………….... 69

A discussion of autonomy views ............................................................ 72

Evidence for competence ................................................................................

An addition to Substantial Autonomy: Threshold Competence …………………... 76

Applying Substantial Autonomy and Threshold Competence................................... 78 
The importance of respect for autonomy …............................................. 81

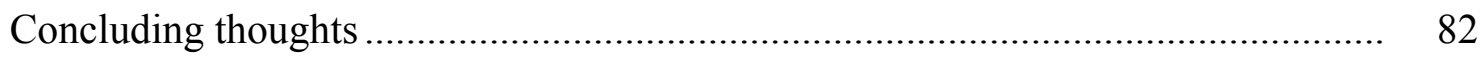

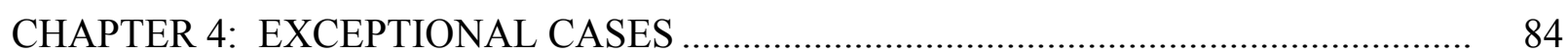

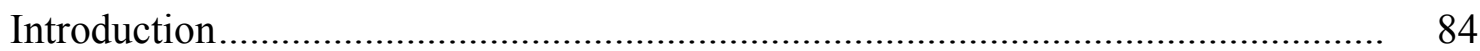

The diagnosis of depression.................................................................. 86

Suicide in patients with depression.............................................................. 88

Suicide in the terminally ill is no more common than in the general

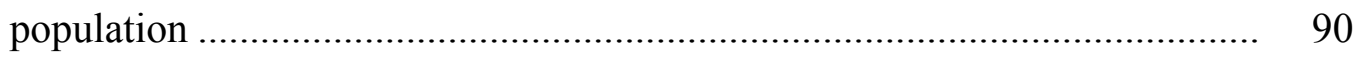

Decision-making abilities of depressed patients are intact ............................... 91

Depression and coherence of end-of-life preferences...................................... 95

End-of-life preferences do not differ between depressed and non-depressed

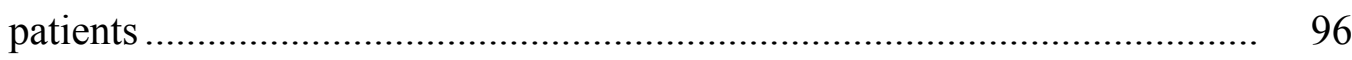

End-of-life preferences endure ...................................................... 97

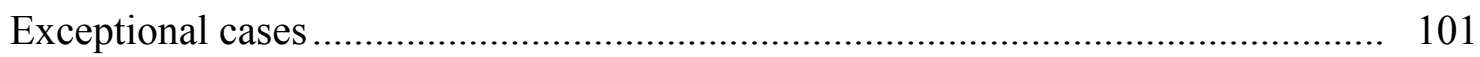

Screening tools of capacity for decisional competence ................................. 102

Applying Threshold Competence to the depressed patient................................. 106

The role of the practitioner ....................................................................... 109

CHAPTER 5: CONCLUSIONS ..................................................................... 112

REFERENCES ….................................................................................... 117 


\section{INTRODUCTION}

In contemporary medical ethics, respect for autonomy (literally "self rule") often is felt to be the most important bioethical principle. The process of obtaining informed consent has been developed as a means to operationalize respect for autonomy. Medical practitioners routinely discuss medical treatments with their patients, providing them information regarding their care choices. This affords the practitioner the opportunity to explain details of her care plan, as well its potential harms and benefits. Additionally, the practitioner is obligated to assure herself that her patient is acting autonomously in making medical decisions. Informed consent requires that the agent have capacity for decision-making (understanding), that the agent be informed (through disclosure of potential risks and benefits of the treatment modality) and that the agent's decision be voluntary. Under most circumstances, patients are presumed competent, and the onus is upon the practitioner to prove otherwise.

This paper pertains to whether the informed consent process is successfully performing the function of assuring respect for autonomy in medical treatment. I argue that informed consent, in its current practice, fails this purpose. In Chapter 1, I begin with a clarification of both the legal and medical meanings of terms such as capacity, competence and autonomy, because these words have been used inconsistently, leading to a good deal of confusion in cases of law, medicine and daily usage.

Next, I discuss how our habit of "agreeing to terms" on websites, without scrutiny, extends to how we approach the informed consent process. I believe that the process of obtaining informed consent has become such a routine and ordinary part of daily practice that patients sign anything put before them. While this may not be 
dangerous to most patients, those who fail to meet the criteria for informed consent can fall through the cracks and go unrecognized. Acting in "best interests" may not be dangerous for most patients, but this is not equivalent to respecting autonomy; rather, it is a form of paternalism. In practice, we are not living up to our ideals, and we are slipping back into paternalism.

Complacency on the part of both patients and practitioners leads to four flaws that have the potential both to undermine patient autonomy and to presume competence where it is absent. I describe these flaws in detail in this chapter. Next, I discuss the need for a sliding scale of competence, rather than a single level of competence, for all cases. It is appropriate to accept less stringent criteria for competence in some situations, but to require a higher level, in others. I point out that while the goal of the informed consent process is to ensure that the patient is "fully informed" of her treatment options, sometimes the patient can only be "as informed as possible". But this presents a dilemma: we need a sliding scale to accommodate different levels of competence for different procedures, yet the sliding scale has the potential to open the door to paternalism. I emphasize the need for practitioners to do their due diligence in assessing patients for competence and to provide explanations above and beyond the minimum required in the consent document. I call this process Rigorous Informed Consent.

But simply advocating that people "do a better job" is insufficient. I propose two solutions for improving the informed consent process. The first involves utilizing additional personnel to ensure that patients are properly informed. I discuss the potential merits and disadvantages to introducing what I call "informed consent specialists" into 
the process. I argue that while this measure may bring additional costs, we should ask ourselves what measures we would wish to take to ensure respect for autonomy.

The second solution I propose involves the implementation of a coding system to define the level of capacity required for a given clinical situation, on a numerical scale. This system bears some resemblance to the International Statistical Classification of Diseases and Related Health Problems (ICD-10), ${ }^{1}$ utilized for billing and coding of medical procedures, worldwide. I detail what such a system would entail and examine the potential advantages and disadvantages that "informed consent coding" would afford.

While not the focus of this work, I have concerns about what I call "exceptional cases," when agents are assumed to be incompetent, simply because they are refusing the treatment that is recommended by their practitioners. These are cases in which patients may wish to forgo care or refuse life-prolonging treatment — even to request physicianassisted suicide (PAS). Under these circumstances, practitioners shift the burden of proof to the patient to demonstrate competence. Such patients raise red flags for medical practitioners who question whether they can meet the criteria for medical decisionmaking because they may suffer from conditions that might "defeat" their capacity, such as severe pain or depression. My assertion is that the informed consent process is not serving the function it should. And if ordinary cases can slip toward paternalism, the exceptional ones will also. In the end, I believe that the solutions I propose may have relevance for both ordinary and exceptional cases.

In Chapter 2, I move to issues of authenticity, including the epistemic difficulties of identifying when patients may be operating under coercive influences. I emphasize the

\footnotetext{
${ }^{1}$ International Statistical Classification of Diseases and Related Health Problems.
} 
difference between voluntariness and authenticity and explore both the philosophical and medical literature pertaining to these issues.

First, I discuss Harry Frankfurt's "real self view” and examine the epistemic challenge that assuring authenticity presents, with the goal of providing insight into how practitioners might best determine that an agent acts voluntarily, in keeping with her values, and therefore autonomously.

Second, I examine the work of Daniel Brudney and John Lantos, who contemplate the ambiguity between authenticity and agency, in evaluating autonomy. Deciding whether to accept authenticity (living one's life in accordance with one's distinctive beliefs and values) or agency (one's capacity to make a choice at a given time) presents a dilemma for practitioners. The authors claim that clinicians tend to look for both components when assessing autonomy, appealing to agency for decisional competence to refuse treatment, but to authenticity when the patient's refusal of treatment seems inconsistent with who the patient is. Inappropriately applying one component over the other is worrisome. I note that using agency, alone, may permit a single, poor decision to override a lifetime of established values. However, practitioners may go too far in the other direction and reject any choices made under agency, citing authenticity as their basis, thus acting paternalistically. This must be discouraged.

Next, I look to the work of Laura Weiss Roberts, analyzing four domains of influence upon authenticity, from peer pressure to developmental factors, illness-related considerations, psychological issues and cultural and religious values. Then I describe potential "red flags" for authenticity and consent issues, such as signs of peer pressure, abrupt changes in mental state, refusal of treatment, consent to risky treatment, and 
change of mind. Within these descriptions I provide suggestions for practitioners to follow once these situations are identified.

In Chapter 3, I focus on a number of possible views of autonomy, with the goal of formulating the best view. I describe the work of Tom Beauchamp and James Childress, Joel Feinberg, Gerald Dworkin, and Allen Buchanan and Dan Brock.

Here I present my own formulation of what elements are required for autonomous agency and introduce the concepts of Substantial Autonomy and Threshold Competence. I discuss how the most rigorous conceivable standard for competence is not always the most appropriate one. "Full autonomy" or "ideal autonomy" is not always possible, nor is it always necessary to attain.

When the criteria are met for being autonomous in a particular context, agents possess what I term Substantial Autonomy. Further, when an agent meets the given criteria for Substantial Autonomy for a given situation, she possesses what I call Threshold Competence for that decision. Threshold Competence varies for the particular situation at hand. When an agent possesses Threshold Competence, she has the minimal, particular competence required to make a decision for a particular situation. Situations involving greater potential patient harm, experimental therapies, forgoing life-extending treatments, or requesting assisted suicide clearly warrant greater scrutiny and a more rigorous approach to informed consent.

Next I address how Substantial Autonomy and Threshold Competence might be applied to real-world situations. I emphasize that standard capacities exams or the coding system I suggest can be implemented to assist in establishing that an agent possesses Threshold Competence for a given treatment, but even so, consideration of the agent's 
real self views is paramount. While assessment of authenticity presents a great challenge, its pursuit should not be dismissed as a mere philosophical ideal. Philosophy informs the practice of medicine and medical ethics, and the development of a viable autonomy view will assist medical practitioners who face such ethical dilemmas.

My hope with this project is to improve the informed consent process in medical practice, through the measures I suggest. Not only can it overcome the flaws I see with the process employed currently, but it can address the exceptional cases, as well. In Chapter 4, I focus on the competence of patients with depression who may wish to refuse a given treatment plan, or even request PAS. These patients receive my attention because such cases have been used as examples in the literature and in practice for overriding patient preferences. The very fact that a patient wants to end her life is provided as a reason to doubt her competence. This line of reasoning has been extended to anyone wishing to forgo life-extending medical treatment; that one would wish for a shorter life (of any quality) calls into question one's competence. In these situations, preserving a patient's life is put before respect for autonomy, in a paternalistic fashion.

Here I provide factual background regarding depression as it pertains to suicide risk, medical decision-making, and end-of-life preferences. I cite studies that show that people with depression nevertheless are competent to make medical decisions in four ways. Research indicates that suicide is no more prevalent in the terminally ill than in the general population, that depressed patients maintain both their capacity for decisionmaking and appreciation of their situation, that preferences for the end of life amongst depressed patients are similar to those without depression, and that patient's preferences are stable over time, even after treatment for depression. 
I conclude this chapter with a description of assessment tools of capacity and explain how Threshold Competence can be applied to depressed patients. While those with severe depression may lack competence, I argue that mild to moderate depression does not significantly alter patients' preferences, so the wishes they express should be taken as reliable and authentic.

In my Conclusion, I summarize my project and describe some of its limitations. I note that implementation of informed consent specialists could be costly, and the informed consent coding system would require resources and interest on a grand scale. Nonetheless, the fact that coding systems such as ICD-10 are utilized worldwide establishes precedence for such a program. Beginning with a small-scale rollout would be the most feasible approach.

Epistemic limitations to our own motives and the real self values of others may seem daunting, but the fact that we hold agents to be autonomous, in the real world, means that finding a practical approach to the informed consent process is essential. Recognition that agents need not be perfectly autonomous, but merely "autonomous enough" guides my development of the requirements for Substantial Autonomy and Threshold Competence. While some believe that the informed consent process is in itself paternalistic, I believe a sliding scale for autonomy decreases the risk of hard paternalism (with setting the bar too high) while preventing those who lack competence from making potentially dangerous decisions (with setting the bar too low).

Few studies and small case samples limit the certainty with which I can draw conclusions about the exceptional cases. Nevertheless, I believe that those with mild to 
moderate depression can make authentic choices about their care, including the refusal of treatment or PAS. 


\section{CHAPTER 1: PROBLEMS WITH INFORMED CONSENT}

\section{Introduction}

Since the 1960's, patient autonomy has received increased attention in medical ethics. Respect for autonomy (literally "self rule") often is felt to be the most important bioethical principle. Emphasis on autonomy has increased as a result of works by Ruth Faden, Tom Beauchamp and James Childress, which include the US President's Commission (Faden and Beauchamp, 1986, p 8) ${ }^{2}$, the National Commission for the Protection of Human Subjects of Biomedical and Behavioral Research, (1979, section b (1), pp 282-30) ${ }^{3}$ and the President's Commission for the Study of Ethical Problems in Medicine and Biomedical and Behavioral Research, (1982, p 27) ${ }^{4}$.

In response to this change from a more paternalistic model, in which decisions of physicians rarely were questioned, the process of obtaining informed consent has been developed as a means to operationalize respect for autonomy. Informed consent is a legal construct, focused on the disclosure of information to the patient and the promotion of autonomy. ${ }^{5}$ The practice of obtaining informed consent gives the patient an opportunity to agree to or reject a given treatment modality, while providing the practitioner occasion to assess the patient's capacity for decision-making. Kutner, et. al. state:

In order for consent to be valid, conditions of disclosure of information, competency, understanding, freedom from coercion and presence of decision making must be met. In theory, true informed consent occurs when a physician

\footnotetext{
${ }^{2}$ US President's Commission, Faden and Beauchamp, 1986, p 8.

${ }^{3}$ National Commission for the Protection of Human Subjects of Biomedical and Behavioral Research, 1979, pp 282-30.

${ }^{4}$ President's Commission for the Study of Ethical Problems in Medicine and Biomedical and Behavioral Research, 1982, p 27.

${ }^{5}$ Berg, 1995-6, p 346, fn 4.
} 
provides information to a competent patient who understands the data and voluntarily makes a decision to accept or refuse the recommendation. ${ }^{6}$

Kutner et. al. identify here three essential elements of informed consent: that the agent have capacity for decision-making (understanding), that the agent be informed (through disclosure of potential risks and benefits of the treatment modality) and that the agent's decision be voluntary. Under most circumstances, patients are presumed competent, that is, able to fulfill these three requirements, and the onus is upon the practitioner to prove otherwise. Patients are provided information regarding their care choices and then are asked to consent to the treatment proposed by their practitioners. In practice, agents are presumed to be autonomous (that is, competent) when they can cooperate with their care, discuss treatment options and make day-to-day decisions. Ideally, the patient and physician build a relationship in which the patient feels comfortable in asking questions and the physician respects the patient's choices.

Viewing competence as requiring these three elements is to take a broad view of competence. A more narrow view of competence looks only at questions of capacity, that is, evidence of logical reasoning about the information provided to the patient. I think this is too limited a view, but such an interpretation may stem from confusion over the terms "capacity" and "competence." I will clarify.

"Capacity," "autonomy" and "competence" are not synonymous. Capacity refers to a patient's present level of decision-making ability, which can vary over time. It is a component both of competence (in my view) and of autonomy. Autonomy refers to the capacity (intellectual or rational) to make independent decisions, free of confounding

\footnotetext{
${ }^{6}$ Kutner, et. al., 1991, p 1404.
} 
factors. Competence refers to the ability to perform a particular task. ${ }^{7}$. An agent may have the competence to select from a dinner menu, but not to make decisions about her medical care or her finances. For the purposes of medicine, and for this discussion, competence for medical decision-making is demonstrated when an agent meets the criteria for informed consent. What adds some misunderstanding is that competence also refers to legal restrictions, such that an incompetent person is legally prohibited from making certain decisions. ${ }^{8}$ So, we find we must deal with two types of competence: legal (de jure) and clinical (de facto). ${ }^{9}$ Legal competence is a judicial determination, while clinical competence is a judgment made by a clinician, reflecting the capacity of a patient at a point in time. ${ }^{10}$ A judicial competency hearing may take weeks to accomplish. Due to the urgency of medical conditions however, practitioners may be called upon to render an opinion regarding a patient's "clinical competence," i.e. her capacity for medical decision-making, in light of her being informed and acting voluntarily.

Ideally, competence should be used only as a legal term. ${ }^{11}$ Due to colloquial use, and use within the philosophical and medical literature however, for the purposes of this work I will refer to competence as the ability to provide informed consent based upon having capacity, being informed and acting voluntarily. I will discuss how different clinical situations may require different types or levels of competence, and hence different types or levels of capacity, information and voluntariness. Further, the process

\footnotetext{
${ }^{7}$ Berg, 1995-6, p 347, fn 10.

${ }^{8}$ Ibid., fn 14.

${ }^{9}$ Schwartz and Blank, 1986, p 1256.

${ }^{10}$ Ibid., pp 1256-7.

${ }^{11}$ Nichita, 2007, p 54.
} 
of obtaining informed consent is meant to reflect such competence. Thus, a patient may lack competence to provide informed consent, even though she has capacity for decisionmaking, when she is either ill-informed or being coerced, thereby lacking voluntariness. Or, a patient may be free of coercion and have been properly informed, but lack the capacity to make a choice about her medical care. So while, formally, medical practitioners cannot declare a patient incompetent, they can determine that a patient lacks capacity, is ill-informed or lacks voluntariness, and as such cannot provide informed consent.

The process of obtaining informed consent has become a routine part of daily practice, and because it is so ordinary, its components receive little scrutiny. I liken it to "agreeing to terms" on a website, when updating computer software. In my experience, it is not unusual for patients to be asked to sign consent forms as they are conveyed down the hall on a gurney to the procedure room. For the practitioners, obtaining consent is just so much paperwork to make things "official;" little effort or time is spent on explanations. Often, staff will try to be "helpful" by "summarizing" the forms for the patient. "Oh, this just gives us permission to treat," or, "This form says that you understand that there are risks to any surgical procedure." Those who wish to slow down and actually read the forms may feel pressure simply to "sign on the dotted line" without reading the documents. And as "terms and conditions" become ubiquitous, from web sites to computer applications, we as consumers have become conditioned to "agree" to anything that should pop up before us.

That we give the informed consent process short shrift may not be dangerous to most patients, as most patients are competent, undergoing routine (not experimental) 
treatments, with a general assumption that the treatment to which they are agreeing is in their own best interest. Because little scrutiny is given to the informed consent process, however, patients who fail to meet the criteria for informed consent can fall through the cracks and go unrecognized. We may assume that a patient has capacity, when in fact she does not, for example. For the most part, the end result is not disastrous. Patients with confusion, or who lack a grasp of the treatments or procedures to which they agree, receive good care, nonetheless. They might agree to the treatment, were they of sound mind or better informed. But acting in "best interests" is not equivalent to respecting autonomy; rather, it is a form of paternalism, albeit benign. While some paternalism, I argue, is necessary or at least unavoidable, we should not allow ourselves to become complacent. In practice, we are not living up to our ideals, and we are slipping back into paternalism.

A different type of situation that brings problems with informed consent into relief involves what I call the exceptional cases. This is when agents are assumed to be incompetent, simply because they are refusing the treatment that is recommended by their practitioners. These are cases in which patients may wish to forgo care or refuse lifeprolonging treatment — even to request physician-assisted suicide (PAS). Under these circumstances, practitioners shift the burden of proof to the patient to demonstrate competence. ${ }^{12}$ These patients raise red flags for medical practitioners, because there is some question about whether they can meet the criteria for medical decision-making. These patients may suffer from conditions that might "defeat" their capacity, such as severe pain or depression. When these patients ask for controversial measures-PAS for

${ }^{12}$ Burnell, 1995, p 510. 
example - there is great concern about the patients' ability to decide. An in-depth exploration of the issues of PAS is beyond the scope of this work. My assertion is that the informed consent process is not serving the function it should. And if ordinary cases can slip toward paternalism, imagine what must happen to the exceptional ones.

In this chapter I analyze the informed consent process, identify problems in practice and offer solutions that might be implemented in the real world practice of medicine. My goal is to optimize the informed consent process and ensure that practitioners abide by their duty to respect patient autonomy.

\section{Problems with current practice}

A curious feature of the current system of informed consent is that there is no consistency to the approach for determining if an agent is competent. Practitioners may employ a range of standards for competence, and there are no guidelines for when any of them might be appropriate. Kutner, et. al. describe five different approaches to competence in the current system of informed consent: 1) expressing a choice; 2) choice with a "reasonable" outcome; 3) choice based on "rational" reasons; 4) ability to understand; and 5) appreciation of the situation and its consequences. ${ }^{13}$ Each of these approaches places increasing demands upon the patient to demonstrate understanding and manipulate information, focusing primarily on capacity. One practitioner might accept the mere expression of a choice, while another might demand evidence of rational choice, as well as communication of understanding of the harm/benefit analysis, for a given

${ }^{13}$ Kutner, et. al., 1991, p 1405. 
treatment plan, clear demonstration that the agent is well-informed. ${ }^{14}$ Or, one could apply the same approach, be it rigorous or undemanding, to all of her patients, regardless of the situation. What is not clear is what the "right" approach should be.

It might seem obvious that, ideally, the most rigorous conceivable standard always should be the benchmark for competence, as it entails the highest standard of insight and comprehension. However, it may be appropriate to accept less stringent criteria for competence in some situations, such as life-threatening emergencies (when implied consent ${ }^{15}$ applies), or when treatment risk is quite low (as in the case of an obvious fracture). The goal of the informed consent process is to ensure that the patient is "fully informed" of her treatment options and their consequences, as well as alternative therapies and consequences of refusal. But sometimes the patient can only be "as informed as possible". Additionally, some patients may wish to give carte blanche to their doctors, who "know best". And some patients, though rational and of normal intelligence, may not fully appreciate the potential consequences of their decisions.

Practitioners should be carefully and deliberately applying the elements of informed consent to each of their patients. Rather, complacency has become the norm. This leads to four flaws with the informed consent process that I identify, below.

\section{The "Expedience Problem"}

The first flaw I call the Expedience Problem, or "taking the easy way out." It may be more convenient for the practitioner to accept the appearance of ability to reason for

\footnotetext{
${ }^{14}$ It is also possible for there to be a failure on the part of the practitioner to provide relevant information, which prevents the agent from being truly informed and therefore competent for decision-making. This will be discussed, shortly.

${ }^{15}$ Under "implied consent" practitioners assume that the patient would want to be treated as a "reasonably prudent person" with the same condition would wish to be treated, were the patient able to consent.
} 
many clinical situations, than to probe deeper into the patient's comprehension of the matter at hand; it is a failure to fully assess capacity. This involves an explanation of the need for a test or procedure provided to a patient with apparently normal comprehension, followed by agreement to the plan by the patient. Since the patient does not object and is agreeable to the plan, no deeper exploration of the situation is pursued. (Were she to question the plan, this problem would be avoided, since doing so would call attention to issues of capacity [comprehension, ability to reason] and prompt the practitioner to more thoroughly assess this component.) Even if the practitioner provides a detailed explanation, she fails to assess the patient's capacity, adequately. Whether the patient has capacity or not it is not adequately assessed. Thus, the patient cannot be said to have given informed consent.

One can overcome this flaw by requiring a higher standard, one that involves not simply assessment of rationality, but also looks for comprehension of the situation and provides a description of potential harms and benefits. This compels the practitioner to provide the requisite information to the patient and to better assess the patient's understanding. While this may be the case, this standard is troublesome because the process of assessing understanding inevitably involves the tester's view of what constitutes understanding. If insufficient information is provided to the patient initially, or if the method used for testing understanding is questionable, a disproportionate number of people may be found incompetent. ${ }^{16}$

Perhaps practitioners become conditioned only to probe to a given depth in seeking informed consent out of habit. And perhaps given the harm/benefit ratio for a

${ }^{16}$ Kutner, et. al., 1991, p 1405. 
great many procedures and treatments, this approach is fine, or even appropriate. It is not problematic to accept minimal patient understanding for a great many situations. Indeed, to expect a patient to have the same understanding of medical conditions, tests and procedures that the practitioner possesses is ridiculous. However, it is easy for practitioners to slip into a mode of thinking that assumes that patient agreement implies patient comprehension-but so many times it does not. Practitioners do not do this with malice - they wish what is best for their patients. But when we start to assume that "we know what is best" we risk losing respect for patient autonomy - the very principle that informed consent is designed to ensure.

\section{The "Least Agreement Problem"}

A second flaw similar to the Expedience Problem is what I call the Least Agreement Problem. Here, the practitioner applies the highest standard that she believes is compatible with the patient's choosing what the practitioner thinks is best, while providing the least amount of information or detail necessary to inform her patient. Rather than engage in a lengthy exploration of the patient's capacity for understanding information, making inferences, and dealing with probabilities, the physician chooses the least-rigorous standard that she can, in hopes that she can secure agreement from her patient. Doing more would risk patient refusal.

Suppose a practitioner knows, or has good reason to suspect, that the patient will agree to the treatment she thinks is best if she demands only that the patient demonstrate the ability to reason, but will refuse if she probes more deeply, to question how the patient arrives at her decision to proceed. Such a situation is similar to "therapeutic privilege," in which a practitioner withholds information she feels will pose a 
psychological threat to the patient and imperil the patient's physical health. ${ }^{17}$ (This may also be invoked when full delineation of a procedure's details might cause the patient to forego a procedure the practitioner believes to be in the patient's best interest or the best option for improved quality of life or survival. It is not intended to permit the practitioner to withhold information that she believes will cause the patient to refuse treatment, but rather to withhold information that will so upset the patient that rational decision-making will be precluded. ${ }^{18}$ ) In this case, the practitioner truly believes that her treatment plan is the proper one, but rather than invest the time in talking with her patient to convince her of this, she seeks a lower test of competence. This is a matter of not asking the question, for fear of hearing an answer one does not wish to address. (Perhaps the patient believes the procedure will confer upon her super-powers, or, to be less flippant, will restore her fertility [when it will not] or eliminate her pain [which cannot be guaranteed.]) Again, practitioners do not have malice in mind, but at times they may not do their due diligence. A sliding scale regarding competence without rules allows for paternalism to sneak in the back door, be it subconsciously or consciously, on the part of the practitioner.

The Expedience Problem and the Least Agreement Problem involve failure to inform and assess the agent, appropriately, in such a way as to ensure that paternalism is not introduced. In hard paternalism, a patient's autonomous choices are overridden, even when there are no concerns for a patient's competence. With soft paternalism, practitioners impose upon patient autonomy to protect a patient from possible harms when they believe her decisions are not informed or are not voluntary, and thus are not

\footnotetext{
${ }^{17}$ Segen's Medical Dictionary, p 725.

${ }^{18}$ Meisel, Roth and Lidz, 1977, p 288.
} 
autonomous. ${ }^{19}$ I do not insist that all paternalism must be eliminated. At times, acting paternalistically may be necessary. Other bioethical principles, such as beneficence, may override respect for autonomy. Perhaps hard paternalism sometimes can be justified, but this will not be resolved here. The situations I wish to address involve soft paternalism.

\section{The "Defeater Problem"}

Another paternalistic flaw is seen with the Defeater Problem, when providers override the wishes of the patient, due to circumstances such as pain or depression, conditions which can impair competence, but do not necessarily do so. The practitioner "jumps to conclusions," thinking the patient "fails the test" for informed consent due to lack of capacity, but in fact has capacity. The practitioner assumes that "it is the pain talking," and that the patient is only asking for an escape from those circumstances; she "really" does not wish to end her life or hasten death. It is possible, perhaps even frequently the case, that patients cannot meet competency requirements when suffering from these conditions. But with the Defeater Problem, these "defeaters" of capacity are assumed to render the agent incompetent, even when they do not necessarily do so.

\section{The "False Consent Problem"}

If the Defeater Problem can be thought of as "jumping to conclusions," then the False Consent Problem can be thought of as "jumping to the opposite conclusion." It consists of cases in which the assessor believes an agent meets the criteria for providing informed consent, yet she fails to meet all three elements of capacity, being informed, and acting voluntarily. It is similar to the Expedience Problem, but here the patient's capacity and/or voluntariness truly are impaired, yet go unexamined. The assessor may

${ }^{19}$ Lo, 2013, p 35. 
assume that the patient chooses a therapeutic course of her own accord, when she is being coerced (to appease family members, for example), is under the influence of a mindaltering substance, or is experiencing pain, depression or other distractors. This is the opposite of the Defeater Problem, because in this case, the patient's competence truly is impaired, yet the impairment goes unrecognized.

An example of this is described by Weinstock, et.al., who analyzed requests for competence exams by the psychiatry service at a Veterans Administration Hospital. "Patient H," an 88-year-old man with a history of Parkinson's Disease, peptic ulcerative disease and cerebrovascular disease, also was found to have a large left frontal mass. Consultation was requested by the surgeon, prior to surgery to remove the brain tumor. The authors note that this request was made, even though the patient already had consented to surgery. The psychiatrist's assessment, however, found that the patient showed no ability to understand his current medical condition, nor to appreciate the risks of surgery, even after they were carefully explained to him. The assessor found that the patient was oriented to person, place and situation, but not to date. They believed him to have only mild dementia, but felt that since there was "a high threshold for competence to consent to this procedure... he did not meet this threshold and was incompetent to give informed consent to this procedure." 20

\section{Creeping paternalism}

What the four problems I have identified, above, share in common is that they allow paternalism to creep in the back door. With the Expedience Problem and the Least Agreement Problem, the practitioner fails to ensure that the patient has capacity and is

${ }^{20}$ Weinstock, 1984, p 122. 
properly informed. Without proper information, the patient cannot make an autonomous decision. In the Defeater Problem, the practitioner jumps to the conclusion that the patient lacks capacity, and substitutes her own judgment, improperly. And with the False Consent problem, the practitioner fails to recognize the agent's impaired capacity, and proceeds under the assumption that the patient is competent. Usually soft paternalism, while ethically questionable, turns out to be in the patient's best interests, at least from a medical standpoint. But the complacency and ease with which we have come to accept practices, ranging from laziness to brazen disregard for autonomy, in the name of soft paternalism, is troubling. Knowing that such practices are commonplace makes me worry about the exceptional cases, in which patients suffer from terminal illnesses or degenerative diseases that result in pain or reliance upon artificial means to sustain life. All too often, the exceptional cases must endure their worst fear: continuing to live, when they do not wish it. Flaws within the process of assessing competence allow practitioners to override the wishes of these patients. They impose their own agendas on them in their failure to respect patient autonomy.

\section{A brief discussion of paternalism}

Paternalism refers to interference of a state or individual with another person, against his or her will, motivated by a claim that the person would be benefited by that interference. One question I must address is whether some paternalism in medicine, if any, is permissible. ${ }^{21}$ In emergency situations, "implied consent" allows for practitioners to aid a person who is impaired by her medical condition and unable to provide informed

${ }^{21}$ Gerald Dworkin provides an overview of terminology (hard vs. soft, broad vs. narrow, weak vs. strong, pure vs. impure and moral vs. welfare) to which the reader might refer. Dworkin, 2010, pp 4-5. 
consent. More controversial is short-term suicide intervention to attempt to assist the suicidal person, who might express regrets later. Practitioners are to act as a "reasonably prudent person" would have them act. For example, an unconscious victim of a motor vehicle crash would wish for the trauma surgeon to operate to repair her injuries, if she were of sound mind, so the surgery should proceed.

It is when practitioners go beyond these situations that their actions are of concern. Dworkin discusses several approaches to analyze how much paternalism is acceptable. He asks under what, if any, circumstances can the presumption that paternalism is wrong be overcome? From the standpoint of consequentialism, he notes that there may be some conditions in which paternalism should be allowed, because doing so does more good than harm. He adds, however, that this weighing is not simply an empirical matter. It also depends on our understanding of the good of persons.

If the good simply included items such as longer life, greater health, more income, or less depression, then it makes it look like an empirical issue. But if we conceive of the good of individuals as including times such as being respected as an independent agent, having a right to make decisions for oneself, or having one's autonomy not infringed, then the issue of whether the agent is better off after being paternalised is partly a normative matter. ${ }^{22}$

What we must consider, then, is if it is right to act paternalistically sometimes, accepting soft paternalism, where it is permissible to intervene "to provide information, or to point out defects in our rationality" 23 when we are not acting fully voluntarily, but to respect choices made voluntarily, even when they may not be for our own "good".

I argue that situations in which soft paternalism is employed are largely these "benign" ones, where an addlepated elderly woman with a broken hip is guided toward

\footnotetext{
${ }^{22}$ Dworkin, 2010, p 7.

${ }^{23}$ Ibid., p 8 .
} 
"choosing" surgery, as it is "best for" her overall condition. I argue that our goal should be to maximize respect for autonomy so far that it is possible. Part of this involves the notion of sliding scales of capacity and competence--that some situations require the highest level of comprehension and insight, while others do not. We can imagine cases in which treatment choices are obvious, even to those with mild dementia. And we can imagine others that demand the highest level of capacity. I will discuss this shortly and in greater depth in Chapter 3. But the exceptional cases are not these situations. Rather, they are the cases where a patient makes clear requests (to end treatment, for example) that may run counter to the practitioner's advice. These patients are not apathetic, but rather, engaged in their care and emphatic in their requests. For these patients, paternalism is not benign, at all, and the consequences of acting paternalistically are ethically problematic. I assert that when people meet criteria for consent-especially when at the highest level — their wishes should be honored.

\section{"Best for" terminology and paternalistic language}

It is important to mention that some of the common language of medicine, possibly due to its paternalistic heritage, carries with it phrases that smack of paternalism, even where no paternalism is at hand. I mention this to dispel confusion about what is already a complex issue. Physicians, through the tradition of medicine, have been encouraged to do what is "medically best for" their patients from a physiological or medical standpoint. And for quite some time, consideration of what the patient thought was "all-things-considered best for" herself physically, emotionally, financially, and so on played only a small role in the physician's calculations. Thus, practitioners often 
discuss what is "good for" a person's health, from smoking cessation to prescription of medication to treatment recommendations. But this is not always a paternalistic action.

I once had a patient who was rather short of breath due to a cardiac condition, requiring hospitalization to stabilize it. I wished to transfer him to a tertiary care facility, better able to manage his issue, because better specialty care would be available to him there. However, the patient did not wish to leave the local hospital and said that if I tried to transfer him, he would simply leave the hospital against medical advice (AMA), instead. I was placed in a difficult situation of not wishing for my patient to leave (which would almost guarantee greater harm to him, due to clinical deterioration), but knowing that what was "medically best for" him would be to be transferred. There was no way to compel the patient to stay in any hospital, as the patient was fully competent and informed. I opted to admit him to the local hospital, but not without a great deal of arguing with the hospitalist (the practitioner in the local hospital, who was taking admissions). The hospitalist wished to refuse to admit the patient, because of the nature of his condition, notwithstanding the fact that if the patient left AMA, he would deteriorate or even die. My argument was that we should do what was "good for" the patient all things considered (admit him locally) even if it was not "medically best for" him. At no point, however, was my consideration a paternalistic one. Acting for the patient's best interests involved no violation of his rights to choose-in fact, it honored his capacity for decision-making, even though he was not making the best choice for his own care. Sometimes the language of "patient good" belies the fact that we act in ways that respect, rather than violate, patient autonomy. 


\section{Potential solutions: the importance of flexibility and the need for due diligence}

I have outlined problems I see with the informed consent process. All four of these flaws are what can be termed "enforcement problems." That is, they are problems in practice, not in theory. As such, they can be remedied by better enforcement of rules for better practice for practitioners. Next, I would like to address potential solutions.

What the Expedience Problem and the Least Agreement Problem share in common is the fact that the practitioner can select the standard of competence that she wishes to apply. The Defeater Problem and the False Consent Problem involve jumping to conclusions about a patient's competence. One solution would be to mandate a certain (middle-of-the-road) standard and apply it to all situations. In some ways, this is what is accomplished with standardized consent forms. The "Consent to Surgical or Other Medical Procedure" form utilized where I practice has ten numbered sections to be completed by the practitioner and the patient. To summarize, it names who is performing the procedure and its purpose; acknowledgement that "alternate means of therapy have been discussed" 24 including the right to refuse the procedure, as well as options available should the agent refuse, and expected consequences of refusal are included. Risks of the procedure, as well as consent for anesthesia, administration of blood products (or their refusal) also are noted. That "unforeseen conditions may necessitate additional or different procedures" as well as awareness "that the practice of medicine and surgery is not an exact science" are explicit in the document. ${ }^{25}$

What becomes apparent when examining consent documents such as this one is that assurance of a patient's "ability to understand" is not assessed utilizing the

\footnotetext{
24 "Consent to Surgical or Other Medical Procedure".

25 Ibid.
} 
document, itself. While the document says, "I understand that this procedure is for the

purpose of..."26 it is possible for patients to sign without understanding the procedure and its purpose--or even to sign without actually reading the document. The burden is placed upon the patient to ask questions and clarify issues in order to make sure she understands the procedure, rather than on the practitioner who obtains the consent.

This "buyer beware" attitude evident in the consent form truly is the minimum standard for consent. Practitioners can shape the document to be more explicit, if they desire. They can list many risks and benefits. Apart from the contents of the informed consent document, practitioners can have lengthy dialogues with their patients about the procedure, its risks and alternatives. But the consent document, itself, does not constitute informed consent, per se. It merely documents that a conversation took place. It is up to the practitioner to be certain that the patient's skills of comprehension and rationality are sufficient to the task. The practitioner still must look for potential defeaters of autonomy, such as pain, depression, peer pressure or intoxication, even when the patient is eager to sign the document.

Now, even if we mandate a given standard, we can see that documentation of consent, per se, does not achieve this goal. We must make sure that the practitioner assesses the patient for her ability to understand. Further, since the consent document, itself, does not include this assessment, the practitioner must take it upon herself to do it. We could include other documentation that demonstrates the patient's ability to understand, through a cognitive assessment, for example. Or the practitioner could attest that the patient meets the criteria for capacity to consent. Note that essentially this is

${ }^{26}$ Ibid. 
what is intended, utilizing the consent document, at present. By allowing the patient to sign in good faith, the practitioner demonstrates her own good faith effort, having assured herself that the patient is indeed competent for medical decision-making. This means that even without added documentation, we can implement a mandatory standard.

But this may not be appropriate. That criteria for capacity are somewhat nebulous affords practitioners a great deal of freedom. In some ways, this is good, as it allows an important flexibility to accommodate a range of situations, differing with respect to risk of harm, severity of illness, patient competence and so on. There is little doubt that a patient with a badly angulated extremity fracture should have the fracture reduced and undergo surgery, if necessary. The consent process is almost a formality, as even a person with limited intellect can understand the need to "fix a broken arm". ${ }^{27}$ The surgeon still has discretion as to what surgical technique to employ and what orthopedic hardware to select, to perform the repair of the fracture. It is not the role of the patient to make these technical decisions.

Practitioners are afforded a similar type of flexibility with the consent process, so that they might quickly (and appropriately) tailor the process to the patient. Standard consent forms require a minimal description of the procedure, as well as its anticipated benefits and potential harms. But practitioners are free to expand their descriptions as they see fit. A patient of normal intelligence undergoing surgery for breast cancer can expect a detailed description of the lumpectomy, lymph node dissection and anticipated healing time. Potential deformity, the need for drain placement, reconstructive options and the biopsy procedure are likely topics of discussion. Not all patients might require

\footnotetext{
${ }^{27}$ I give greater attention to this issue in Chapter 3.
} 
such detail, or they might prefer not to have such information. That a patient wishes to "decline to be informed" is not without controversy, ${ }^{28}$ but is not an infrequent occurrence. Some elderly people who have become accustomed to a more paternalistic approach in medicine feel comfortable "leaving it to the doctor" to decide what is best. Also, cultural differences that leave decision-making to family members are not uncommon. In these situations, and in others I will discuss, the physician does what she thinks is "best for" her patient. But this is not necessarily respecting autonomy. It is a best interests decision. ${ }^{29}$ Too much freedom may allow paternalism to sneak in, where practitioners fail in their duty to respect patient autonomy through the informed consent process. At times, practitioners (for a variety of reasons) may employ whatever standard of capacity they wish, and provide "just enough" information to lead their patients to approve what they think is the correct course of action. But there is a fine line between "therapeutic privilege" and the Least Agreement Problem.

We find ourselves in a dilemma: we need a sliding scale to accommodate different levels of competence for different procedures, but the sliding scale opens the door to paternalism. As discussed previously, some situations do not require a rigorous standard, while others require the highest level. And we have seen that mandating higher standards does not ensure that capacity is present. The first thing we must do to is compel practitioners to be rigorous in their assessments and to provide explanations above and beyond the minimum required in the consent document. They should not let ill-informed patients sign consent forms, and they should do their due diligence in

\footnotetext{
${ }^{28}$ Hyun, 2002, p15.

${ }^{29}$ When patients relinquish their right to decide for themselves or to be informed, it can be argued, they are making an autonomous decision to do so. So, respecting this choice is a form of respect for autonomy.
} 
assessing the patient's capacity. In this, practitioners are duty-bound. I call this process Rigorous Informed Consent. But this is not enough. For this reason, I propose two potential solutions to the informed consent process, which I discuss in the following two sections.

\section{Potential solutions: informed consent specialists}

Being rigorous with regard to the informed consent process sounds like something we already should be doing. Yet patients continue to fall through the cracks. Perhaps making the informed consent process an institutional issue, rather than relying upon the practitioner's due diligence, is required. That institutions already utilize standardized forms to obtain informed consent means that some institutionalization already is in place.

But we could go further and compel practitioners to utilize an "informed consent specialist" to perform the consent assessment. This would be an employee (perhaps of the hospital, but independent of the physician) assigned the task of obtaining informed consent from the patient, and ensuring that she meets the informed consent criteria. The specialist would serve as a patient advocate, to help explain the proposed treatment plan, help assess the elements of informed consent, and ensure that alternative options (including no treatment) have been discussed with the patient.

One problem with this would be medico-legal, in that someone other than the person performing the procedure would be obtaining the consent. The patient would not have the opportunity to ask questions of her surgeon, for example. She could argue that she was not properly "informed" since she could not have her questions answered appropriately. 
However, we could mandate that the practitioner be present during the interview with the informed consent specialist, so that any questions might be answered at that time.

I have one concern about such "institutionalization." I think it is inappropriate to "unburden" practitioners from the informed consent process. Practitioners are best suited to assess the patient because they have an established relationship, as in the physicianpatient relationship. In cases where the surgeon is merely asked to consult on the case, she still is compelled to establish appropriate communications with her patient. Even if the surgeon's participation in the case is minimal (to place a percutaneous feeding tube in a patient in the medical intensive care unit, for example) she is not absolved of the need to properly inform her patient of the potential harms and benefits. Furthermore, I argue that when the physician-patient relationship has only been a brief one, this only serves to emphasize, more strongly, the importance of performing Rigorous Informed Consent.

However, physicians might object to the mandate requiring a third party, an informed consent specialist. Such specialists could be perceived as "meddling" in the physician's business, potentially overriding their diagnostic conclusions about what constitutes appropriate care for the patient, or infringing upon the confidential physicianpatient relationship. This is a reasonable objection, provided it is not motivated by a desire to maintain the status quo; the status quo brings about the Expedience Problem and the Least Agreement Problem. It is possible that patients might trust their physicians, and not wish to introduce a third party into the discussion.

However, third parties already participate in this process. Insurance companies, hospital staff and innumerable other "parties" are needed to perform many medical 
procedures. While discussions with physicians are made in confidence, a great many people either are privy to the fact that a procedure is scheduled or are directly participating in performance of the procedure. While people are resistant to change, perpetuating paternalism by maintaining the status quo, for its own sake, should be discouraged.

Another issue would be cost. First, employing informed consent specialists in the numbers required to obtain consent for the multitude of procedures performed in hospitals, clinics and doctors' offices across the nation might be prohibitive. Second, we should consider the additional time the practitioner would have to spend to perform the consent with an informed consent specialist, rather than during, say, a pre-operative visit. Practitioners already obtain consents for procedures, but use of the informed consent specialist adds another step. If the practitioner must be present during this, it robs her of time that could be spent with other patients, i.e. generating revenue for her practice.

This is, however, a weak objection, if we truly value respect for autonomy. We should ask what measures we would wish to take to ensure respect for autonomy, if cost were not an issue. Changes could then be made to improve the process and ensure that patients are making decisions under the appropriate circumstances, with cost in mind.

\section{Potential solutions: informed consent coding}

Suppose we assume that all practitioners already are practicing Rigorous Informed Consent. Even if this is the case, there is still the question of the standard of capacity to employ. Recall that capacity is a mental skill, pertaining to reasoning and insight. Competence is the (legal) ability to make a decision. Different levels of capacity can be required for competence, and what counts as competence varies by case. So, to be 
competent to make a decision in a given case requires a given capacity, plus assurance that the agent is informed and acting voluntarily.

If we accept that a range of standards for capacity are necessary, an alternative to proposing that a single level be mandated across all cases would be to assign different, mandatory standards for capacity for different procedures--“informed consent coding”, as it were. A single standard could be established for each case, such that the individual would have to meet the established threshold for that situation.

Coding systems are nothing new. Physicians in the United States are reimbursed based upon a coding system known as the International Statistical Classification of Diseases and Related Health Problems (ICD-10). ${ }^{30}$ Diagnoses are assigned a numerical identifier, such as, "Acute appendicitis, unspecified acute appendicitis type, code K35.80."31 These codes are based, in part, upon the procedure performed, the complexity of the evaluation done by the practitioner, the number of organ systems reviewed, the history taken by the practitioner, the time spent with the patient, and other factors. A numeric system is designed to simplify the billing process by specifying the level of care provided and the diagnosis/diagnostic procedure at hand. Without coding there is no billing, and without billing there is no business of medicine.

With informed consent coding, all medical procedures could be coded on a severity scale (let us say from 1-10), with each level of the scale associated with a given demand of rationality, comprehension, etcetera. Thus, a simple, non-angulated, closed (not poking through the skin) forearm fracture that does not require surgery for reduction could be ranked a 1 or 2 . Some surgical procedures (appendectomies for example) and

${ }^{30}$ International Statistical Classification of Diseases and Related Health Problems.

31 Ibid. 
medical procedures (electrical cardioversion, in which a patient is sedated and electricity is used to convert a patient's heart rhythm to normal sinus rhythm) might be ranked a 5 or 6. The decision to undergo liver or heart transplantation, or to request physician assisted suicide would rank a 10 .

The refusal of treatment often prompts great concern, especially when practitioners are convinced that the treatment proposed is the standard of care or is clearly indicated. Refusing an appendectomy, for example, would pose far greater risk of harm to the patient than undergoing the procedure, given the risk of appendiceal rupture and peritonitis if surgery were not performed. Thus, the decision to refuse such a procedure would warrant a higher ranking on the coding scheme than to agree to it. Situations in which there were clinical equipoise might be more equally weighted, as in the case of a patient with Stage IV cancer, for which no treatment is available and the merits of an experimental therapy are unknown. But consenting to or refusing a given treatment constitute different choices, to be evaluated separately; rather than having a single informed consent code for consent or refusal, I advocate two different codes, with one for consent and one for refusal. For all of these cases, the process of Rigorous Informed Consent would be required.

One might think that one could simply apply a higher standard of consent for more expensive (higher ICD-10) procedures, but this is not necessarily the case. For example, a patient with an open ankle fracture (in which the fractured bone has penetrated the skin) obviously requires surgical repair. There is little question of the need for surgery, corresponding to a lower informed consent standard. The inherent risks of surgery (infection, aspiration, allergic reaction to medication) are outweighed by other 
alternatives. Doing nothing risks infection (in high likelihood), deformity (clearly), loss of use of the lower extremity, and (over time) risk of gangrene and even death. ${ }^{32}$ Yet the repair of a compound ankle fracture is far from simple. It may require extensive surgical debridement in the operating room and the use of plates and screws to repair it. The ICD10 code would be high, despite the low consent code.

The challenge of a system of consent coding would be establishing it, on the front-end. While it could be time-consuming and expensive to develop, that the ICD-10 system persists speaks, in part, to its utility. I argue, once again, that the fact that the ICD-10 coding system is in place indicates that the coding process is well established; taking the next step to develop consent coding is in keeping with this type of process.

One may object that consent coding is not possible, is too expensive or is too burdensome. However, the business of training coders, employing coding reviewers (both in hospitals and by insurance companies), not to mention the multitude of coding courses offered belies this objection. Clearly we value coding systems for their utility in calculating revenue. We should ask ourselves how much we value respecting autonomy; if we truly value it, we should be willing to pay for it.

A final objection to this proposal is that it, like the use of informed consent specialists, infringes upon physician autonomy. (It is hard enough to demand the practice of Rigorous Informed Consent.) Physicians (and other practitioners) bristle at the idea of being compelled to do anything, especially if it adds additional work or restricts them from performing their duties in the manner to which they have become accustomed.

${ }^{32}$ Treating non-surgically would reasonably result in any of the above outcomes. 
I imagine that there are practitioners who find the need to obtain a patient's consent, at all, to be an annoyance, if not an affront to their intellect and skill. However, the duty to the good of the patient requires not merely the patient's agreement to proceed, but her comprehension of what the procedure entails, various alternatives and so on; this is the difference from mere consent and Rigorous Informed Consent. Furthermore, as I have discussed, coding systems, based upon diagnoses and procedures, already are in place. Certainly, leaving the question open of what level of capacity to accept for a given case is less dogmatic. But the current process, as I have discussed, is flawed, allowing paternalism to creep in already. I believe that given the ease with which practitioners have become complacent with the current system, providing better-defined criteria for capacities evaluations will result in better-informed patients. And all patients, whether they meet the threshold in a given case or not, will have been better-evaluated and more fairly treated than with the current system.

\section{Conclusion}

What informed and competent people want is shared decision-making, in which the practitioner and the patient discuss a treatment plan and find the best option for them. If we truly value respect for autonomy, we should consider taking steps that, while expensive, will ensure that the elements of informed consent, that is, having capacity, being informed and making decisions voluntarily, are in place. Mandating that a single standard be used for all cases fails, because flexibility constitutes an important aspect of the informed consent process. But a sliding scale, in which potential harms and benefits are matched to a given treatment modality shows promise. This "consent coding" system has the potential to transform how informed consent is obtained. 
Ideally, the process of Rigorous Informed Consent already is in place, as evidenced by the fact that obtaining informed consent is a routine part of medical practice. But flaws such as the Expedience Problem, the Least Agreement Problem, the Defeater Problem and the False Consent Problem plague informed consent as it is currently practiced. Rigorous Informed Consent should be mandatory. Situations involving only brief interactions between patient and practitioner only heighten the need for Rigorous Informed Consent. Utilization of informed consent specialists and informed consent coding has the potential to ensure not only that the patient is well-informed, but to better scrutinize situations when conditions such as pain and depression accompany a disease process.

Yet even the most demanding standards for determining competence, coupled with Rigorous Informed Consent, are not sufficient to establish if an agent is autonomous, in the absence of another element: authenticity, being true to one's self. The informed consent process must ensure that the choices patients make reflect their system of values. In the next chapter I explore the issue of authenticity more fully. 


\section{CHAPTER 2: THE IMPORTANCE OF AUTHENTICITY AND VALUES}

\section{Introduction}

In Chapter 1 I described three components of informed consent: capacity, being informed and voluntariness. Viewing competence as requiring these three elements is to take a broad view of competence. A more narrow view of competence looks only at questions of capacity, that is, evidence of logical reasoning about the information provided to the patient. As mentioned in Chapter 1, I think this is too limited a view. In fact, I think the term "voluntariness," the capacity for voluntary choice, is too limited in scope, failing to capture all that is entailed by an essential component of autonomy: authenticity. Not only do we wish for a patient to make choices freely and without coercion, as defined by voluntariness, but we also wish for those decisions to reflect the agent's genuine values. The element of authenticity is designed to incorporate an agent's values into the consent process. ${ }^{33}$

We recognize how easy it is for people to succumb to pressures, from family members for example, and behave in ways that they might not otherwise. With peer pressure, an agent's expressed desires may not reflect her own values, but rather those of an external source. Other influences may be internalized and become a part of an agent's own psyche, but nonetheless, will fail to represent her authentic choices. We know that it may be difficult to discern when another person is acting inauthentically. Understanding the types of pressures that affect authenticity is essential because we need assurance that

\footnotetext{
${ }^{33}$ I do not wish to enter into the complicated question of values versus desires. Values are guiding principles. We want our actions to reflect these values. The intermediary between values and actions are desires. One can have desires, which can lead to actions that fit with one's values or not. For the purposes of this paper, I am assuming that values are a sub-set of (deeply held) desires.
} 
a patient's choice truly reflects her own values. Further, learning to recognize inauthenticity is paramount, if we are to have confidence that an agent is acting autonomously.

In this chapter, I explore authenticity and values as they pertain to autonomy. A survey of both the philosophical and medical literature provides insight into the concept of authenticity. I describe several elements that influence authenticity and call attention to potential "red flags" that should prompt concern for inauthenticity. I will examine the epistemic challenge that assuring authenticity presents, with the goal of providing insight into how practitioners might best determine that an agent acts voluntarily, in keeping with her values, and therefore autonomously.

\section{Authenticity and the self}

It is common for people to say things and act in ways that differ from what they really believe or want. Whether it is telling a white lie ("Boy, this casserole is delicious, honey!" "I love my annual Christmas sweater, Aunt Jackie!") to agreeing to things we aren't really inclined to do (“Of course I want a big, religious wedding, Mom.") we commonly say and do things that do not reflect our inner desires. Sometimes these things are relatively harmless (unless your spouse's casserole truly is life-threatening). At other times, submitting to peer pressure or acting in inauthentic ways can be more destructive. People can take on morally questionable roles and act in ways that are actually harmful to others or to themselves.

Consider the Stanford Prison Experiment, in which psychologically normal college students assigned to the role of "captors" abused their "prisoners" without 
question, assuming such roles in a matter of hours. ${ }^{34}$ If asked, "Would you beat and humiliate another person you had just met?" most would say 'no'. Yet this is exactly what happened, as a result of peer pressure. People can succumb to "groupthink," preferring to think collectively and maintain unity, rather than to think objectively in evaluating their situation, alternatives and options. Even simply receiving information only from a single, biased news source which supports one's political ideal can evoke hate and distrust of those who disagree with those views. This represents another external force that can influence an agent's beliefs and behavior.

On an individual level, people under peer pressure may behave in ways that they ordinarily might not. This can range from agreeing to "just one more beer" to bullying another person, to agreeing to a medical treatment one otherwise would reject. Knowing when a patient is choosing authentically, then, becomes extremely important to the issue of autonomy.

There is a general phenomenon that we all understand when discussing authenticity, that we may refer to as the "real self." It is common for us to refer to "selves" when speaking about our mental lives. "I'm not myself," or, "She was drinking and wasn't herself," are ways we talk about "authentic" or "real" selves. In practicing Rigorous Informed Consent, the practitioner must ascertain whether the agent's choices reflect her real self values. The problem is, often when peoples' choices are inauthentic, that is, not reflective of their values, they may be unaware of it, themselves. (Otherwise, they might take steps to act authentically.) This is because when agents are aware of acting in a way that is inauthentic, they experience feelings of angst or disillusionment.

${ }^{34}$ Haney, Banks, and Zimbardo, 1973. 
Harry Frankfurt notes than an agent may feel conflicted between how she wants to be motivated and the desire by which she actually is motivated. (The unwilling addict is a typical example.) ${ }^{35}$

In "Freedom of the Will and the Concept of a Person," Frankfurt explores the difference between first-order and higher-order desires. A first-order desire involves "wanting to do $X$." But through self-reflection, a person examines the desires by which she wishes to be motivated. This involves "wanting and choosing to be moved to do $X$." These are higher-order desires. ${ }^{36}$ According to Frankfurt, an agent's effective desire is that which moves her to action. ${ }^{37}$ People act inauthentically when they fail to identify with their effective desires. At times, agents are aware of acting in ways they do not endorse. Wanting to eat a piece of chocolate cake conflicts with my higher order desire to lose ten pounds, so when I eat the cake, I act inauthentically. Agents also are influenced by factors of which they are completely unaware, and this is a common psychological phenomenon that we recognize. Whether one accepts Frankfurt's conception of the real self or not, we appreciate how agents can be influenced by things they do not endorse. The most common way is the indoctrination of beliefs when young that continue to have their force, in adulthood.

Imagine Amy, a middle-aged woman who was raised in a religious and conservative household. Once she left home, she rejected much of her upbringing, choosing to leave her religion and pursue relationships that would have been frowned upon by her family and her former church. Yet despite living her life as she saw fit, she

\footnotetext{
${ }^{35}$ Frankfurt, 1987, pp 32-3.

${ }^{36}$ Frankfurt, 1971, pp 6-7.

${ }^{37}$ Ibid., p 8.
} 
never married, not because she didn't wish to, but because "none of them could stack up". The men with whom she chose to spend time were, in her mind, of questionable moral quality, and therefore "not husband material". It is possible that Amy's judging of all the men she met as "not husband material" is the product of the influence of her religious upbringing, although she feels alienated from those conservative values. Even if one were to say to Amy, "You seem to be influenced by your old religious convictions," she might not agree. Rather, she would only summon vague ideas of what a good husband or good father might be, without reference to religious ideology or values. Amy appears to be motivated by the influences of her childhood, yet fails to identify with them. Such alienation goes unrecognized by the agent, even when confronted with the possibility of its motivating force.

It seems troubling that an agent's desires can be inauthentic, even while she is unaware. Frankfurt and Gerald Dworkin have suggested that the authenticity of an agent's desires depend upon what the agent would endorse, if correct information about why she has the desire were available. ${ }^{38}$ More recently, several authors have gone on to reject Frankfurt's hierarchical theory of the self. Rather, they hold that desires are authentic if they are rationally endorsed, in light of correct information, regardless of level. $^{39}$

Nevertheless, all of these accounts share the idea that no desire can be labeled inauthentic solely due to its content, simply because it is not worth desiring; the procedure of hypothetical reflection is paramount. A desire, regardless of level, can be

\footnotetext{
${ }^{38}$ Frankfurt, 1971 and Dworkin, 1988.

${ }^{39}$ Sjostrand and Juth, 2014, p 120, DeGrazia 2005, pp 99-106, Bruckner 2009, and Christman 2009, pp 155-156.
} 
authentic, upon proper reflection. This implies that how the agent comes to have a given desire does not matter, in itself. So desires that result from "within," such as psychiatric disorders, are not necessarily inauthentic. This can be both helpful or not, depending on the situation. Some desires that result from psychiatric diagnoses may be authentic, if they are desires the agent would have tried to develop, anyway. But an agent may wish to embrace a damaging desire, as in the case of anorexia nervosa (where a patient wishes to be thin, above all else) and depression (where a patient may risk harm or even death). Clearly the account of Sjostrand and Juth has some limitations, and knowing how to assess authenticity becomes the issue. These authors suggest that some test be developed regarding the authenticity of desires, but do not suggest what that test might be. ${ }^{40} \mathrm{I}$ describe some "red flags" for authenticity issues later in this paper. For now, let us look at other practical issues that pertain to authenticity.

In Frankfurt-type examples, an agent is motivated by desires with which she does not identify; her choices, then, are inauthentic. Whether one embraces a hierarchical approach to the real self or not, the problem with authenticity is that it is difficult for us to address in a practical setting. Short of years of psychotherapy, it may not be possible to reveal if an agent's choices are authentic. Ascertaining what an agent would endorse is equally opaque. Suppose it is true that we can never truly know if an agent's desires are authentic. What is the significance for medicine? Maybe the agent can unify her thinking (through therapy or other introspection) and then be enabled to exercise her free will and act on second order desires without pressure. While this is good self-help advice, it does not help for third parties. Further, there is no implication for how

${ }^{40}$ Sjostrand and Juth, 2014, p121. 
practitioners should deal with patients. These epistemic circumstances are such that we cannot be sufficiently confident to ignore the expressed preference, simply because we think it's an inauthentic preference, but we feel uneasy about honoring the patient's wishes.

These matters are too important simply to throw up our hands in frustration. Rather, focusing our attention on authenticity issues can only benefit our patients, if only because it means that practitioners are becoming more aware of this challenging problem. But since evaluating the authenticity of a patient's choice is something we already do (or should be doing), we should examine this practice in greater depth. It is important to understand just what practitioners are assessing, when they seek to establish that an agent is acting autonomously. In the next section, I examine a key question regarding respect for autonomy, addressing the ambiguity that exists between authenticity and agency.

\section{Questioning a patient's choice—-the Authenticity vs. Agency Question}

Practitioners can be troubled when an apparently competent patient makes a choice that seems contrary to her interests, and possibly her values. This becomes most apparent when a patient changes her mind or makes a choice that seems inconsistent with her prior decisions or stated preferences. Daniel Brudney and John Lantos assert that autonomy is ambiguous between the concepts of authenticity and agency. Agency is simply one's capacity to make a choice. Authenticity refers to living one's life in accordance with one's distinctive beliefs and values. Brudney and Lantos note that agency can be fully exercised at an instant, while authenticity must be exercised over time - even over a lifetime. This means that a choice made at a given time may or may not be consistent with an agent's former choices. 
Deciding on whether to act on a patient's asserted choice, at one time, may depend on which type of autonomy (agency or authenticity) the practitioner considers valid. Clinicians, the authors claim, tend to look for both components when assessing autonomy: they appeal to agency for decisional competence to refuse treatment; but when the patient's refusal of treatment seems inconsistent with who the patient is, they appeal to authenticity. ${ }^{41}$ This allows practitioners to apply agency in some cases and authenticity in others, to match what they perceive to pertain to the current situation. Brudney and Lantos believe that practitioners consider both authenticity and agency, simultaneously. When they are congruent, there is no problem. It is inappropriately applying one value over the other that is worrisome. The ambiguity between which value to favor leads to a problem in medical practice, when practitioners claim to be respecting autonomy, when in fact they are not. They end up either turning a blind eye to patients' harmful choices (and calling this respect for autonomy under agency) or questioning the authenticity of a patient's choice, thereby acting paternalistically (and calling this 'best interests' $).^{42}$

The question is, which value (agency or authenticity) is the crucial one? Brudney and Lantos do not believe that agency, alone, is sufficient to justify the refusal of lifesaving treatment. They believe that the exercise of choice at an instant is not sufficiently compelling if there is some question about the veracity of the request. ${ }^{43}$ This means that, for them, authenticity is the basis for autonomy. This is consistent with the current legal guidelines in most states. That is, a search for authenticity (long-held

\footnotetext{
${ }^{41}$ Brudney and Lantos, 2011, pp 221-2.

42 Ibid., p 222.

${ }^{43}$ Ibid., pp 222-3.
} 
beliefs) rather than agency (capacity to make a choice at an instant) is the default action when patients wish to refuse treatment. ${ }^{44}$

At first glance, this seems to be a very appropriate approach. Utilizing agency, alone (and, I might add, at the convenience of the practitioner) can allow her to take solace when patients make rash and potentially harmful decisions. She may turn a blind eye, under the guise of "patient autonomy". And certainly respect for autonomy involves allowing a patient the freedom to make less-than-optimal life choices. Brudney's and Lantos' point is that using agency, alone, may permit poor decisions to override a lifetime of established values that run counter to the new, expressed choice. My concern is, however, that practitioners may go too far in the other direction and reject any choices made under agency, and attempt to override such choices, citing authenticity as their basis. Agents may become aware of new information that alters their preferences and even their values. Ignoring this, using the excuse of authenticity, is a form of paternalism.

Brudney and Lantos are aware of this possibility. They point out that authenticity is not the same as best interests.

The doctor who believes authenticity is important and tries sincerely to understand the basis for her patient's choice in that patient's deeply held beliefs and values is doing something very different from the doctor who decides based upon her own opinion about what is best for the patient. ${ }^{45}$

"Best interest" can be the excuse providers use when acting paternalistically and ignoring a patient's expressed desires. This must be discouraged.

\footnotetext{
${ }^{44}$ Ibid., p 223.

${ }^{45}$ Ibid., p 224.
} 
The authors emphasize that they are discussing authenticity as normative, involving the claims that people tend to have stable and coherent beliefs and values, and that living in accordance with said beliefs is usually a central good for that person. ${ }^{46}$ I have no objection to this, as it allows for what counts as authentic to shift over time, just as an agent's values shift over time (as they most assuredly do), without entailing the search for a pre-existing "true me". ${ }^{47}$ If we may never have access to the true or real self, it can still be helpful to direct attention to the agent's enduring and changing system of values.

Brudney and Lantos also express practical worries, noting that practitioners may be too pressed for time to seek authentic patient choice. Further, doctors may not possess the practical wisdom required to facilitate it. "In practice, it is likely to be much easier to satisfy the conditions for being a competent agent than to satisfy the conditions for making an authentic choice." ${ }^{48}$ In short, it is easier to overlook authenticity, altogether. But this is unacceptable! The attempt should be made to ascertain the authenticity of an agent's choice, not to abandon the search for authenticity. Rigorous Informed Consent, again, must be followed, to avoid this pitfall.

But even with Rigorous Informed Consent in mind, epistemic limitations do not disappear. One traditional (and important) worry is that external forces, such as another person — family, friend, medical practitioner — are unduly influencing an agent's decision.

\footnotetext{
46 Ibid.

47 Ibid.

${ }^{48}$ Brudney and Lantos, 2011, p 225. Here, Brudney and Lantos equate being competent with having capacity, rather than viewing authenticity as a component of competence, along with capacity and being informed.
} 
In the coming sections, I examine how external pressures have the potential to influence an agent's choices and describe how to recognize this occurrence, to ensure authenticity.

\section{External features and pressures}

We know that alcohol intoxication, addiction and family pressures can influence an agent's decision-making capacity. Similarly, they can influence a person's values and the desires she expresses, to the point where she may act involuntarily. Interestingly, it is difficult to find an example of a "pure case" where only an agent's values are changed, while her capacity remains intact. One example might be Stockholm Syndrome, in which an agent can "pass the test" for rationality, but the values she expresses are not her own, despite her assertion that they are. Here, an agent comes to express empathy for her captors, notwithstanding her being held hostage. These feelings are generally considered irrational, given the pain and danger the hostage must endure. Nevertheless, the hostage will reject assistance and even defend her captors - a clear change in values. This leads us to wonder if pain, depression and other factors can have a similar effect.

The Stockholm Syndrome situation is not truly analogous, as agents experiencing pain or depression do not identify with their physiological "captors." Rather, they wish to escape the grip of their condition. In fact, pain and depression can be so distracting and intolerable that agents will ask for anything, including death, to end their suffering. But some influences may go unrecognized by the agent and by external observers. The question is whether these factors can change an agent's values, and whether the new values reflect "true" views, or "false" ones, as in the Stockholm Syndrome case. It is not enough to assess for rationality, since this provides only part of the competency picture. There are really two possible phenomena at hand. For one, a person's expressed desires 
may not reflect her values, as in the case of the lapsed Catholic. Alternatively, the desires expressed by an agent may be distorted by external factors, as with peer pressure or brain washing. In either case, we can look for and recognize spheres of influence to know when either of these two phenomena is occurring. I explore this next.

\section{Authenticity, voluntarism and values}

The first step for a patient to make an authentic choice is for her to make a choice voluntarily. For an agent's decision to be voluntary, she must make it in a manner that is uncoerced. Authenticity, in my view, also requires that an agent's choice be consistent with her personal beliefs and values. Conditions such as dementia cause an "erosion of the self," ${ }^{, 49}$ where the agent loses her personal history, beliefs, motivations and relationships, in addition to her memory, intellect and ability to care for herself. Such losses impair authentic decision-making.

Social elements also can affect authenticity. Emotional distress, institutionalization, language barriers and immigration status may undermine an agent's ability to make choices, independently. Additionally, some medical conditions, such as infertility, or the prospect of living with disfigurement, disability or other self-perceived restrictions on one's liberty can affect the ability to provide informed consent. ${ }^{50}$

As I alluded to at the beginning of this chapter, it is common for people to say things and act in ways that differ from what they really believe or want, for a variety of reasons. We are most familiar with the peer pressure situation in which friends or family members influence agents to do something they might otherwise not consider doing. But there are other elements that affect authenticity, and their influence cannot be

${ }^{49}$ Roberts, 2002, p 706.
${ }^{50}$ Ibid. 
underemphasized. For this reason, I think that the term "voluntarism" is not strong enough to convey the concept; "authenticity" better represents this over-arching idea. This is because traditional accounts of voluntarism focus on cognitive influences, without discussing the external and internal influences of emotional experiences, psychological issues and personhood — elements that contribute to the development of our values and our sense of self. So while authors may refer to voluntarism when discussing this topic, I believe that "authenticity" is what we must mean. Insight into the origins of these elements and the signs of their influence will assist us in developing solutions to issues of authenticity.

One author who focuses more on emotional, developmental and psychological factors, rather than the legal aspects of informed consent is Laura Weiss Roberts. She posits a framework for evaluating voluntarism, ${ }^{51}$ to assess an agent's capacity to make choices with "deliberateness, purposefulness of intent, clarity, genuineness, and coherence with one's prior life decisions. ${ }^{, 52}$ She asserts that voluntarism can be analyzed according to four domains of potential influence: 1) external features and pressures, 2) developmental factors, 3) illness-related considerations, and 4) psychological issues and cultural and religious values. ${ }^{53}$ These are described below. Later in this chapter, I will explain how we can extrapolate from the familiar phenomenon of "peer pressure" to address the other domains of influence she posits.

\footnotetext{
${ }^{51}$ While I disagree with Roberts' use of the term "voluntarism" in this context and prefer the term "authenticity," I will defer to her terminology in this section.

${ }_{53}^{52}$ Roberts, 2002, p 706.

${ }^{53}$ Ibid., p 707.
} 


\section{External forces}

There are times when practitioners suspect that an agent's expressed desires are being unduly influenced by outside forces, leading them to question their authenticity. Problematic are actions that stem from motives the agent does not (or would not) endorse. Roberts points out that the relationship with the caregiver or researcher may have coercive influences, especially when multiple roles or overlapping relationships exist. (A physician enrolling a patient in a study or a family member who also provides physical care of the patient are two examples.) An institutional setting, such as a hospital or nursing home may accentuate this influence by delimiting the patient's personal freedoms ${ }^{54}$ Even the novelty, complexity, seriousness and timing of a consent decision can influence voluntarism.

"Peer pressure" from family members, spouses, clergy and others also can influence the agent and affect her decision-making process. For example, patients may agree to painful or uncomfortable treatment regimens to extend life, for the sake of their families. They may wish to appear strong in the face of a serious disease or note that their family members are not ready to let go. Patients may feel guilty for burdening their families with worry, for "abandoning" them when they die, or for wishing for an end to their own lives, in light of family members' inability to cope with their death. Deciding to have surgery or undergo chemotherapy to spend more time with friends and family is laudable, when authentically chosen. And certainly there are situations in which patients value the psychological wellbeing of their family over their own physical suffering, in an authentic way, but it is the practitioner's obligation, under the practice of Rigorous

${ }^{54}$ Ibid., p 709. 
Informed Consent, to be alert to choices made against one's will. Sometimes these influences may be internalized as well, leading to inauthentic choices.

\section{Developmental factors}

With greater maturity, adolescents gain the ability to reflect upon their own values and consider repercussions of their decisions. Developmentally, with reaching adulthood, they become increasingly able to identify their personal opinions and preferences. Values of mature minor patients should be considered, especially when weighing the potential harms and benefits of medical treatment or its refusal. People lacking sufficient psychological and mental development, however, will not likely have the capacity to provide informed consent in the first place. In such cases, while practitioners can make attempts to consider the values that patients with developmental delays express, ultimately the patient's medical power of attorney would make decisions on the patient's behalf.

\section{Illness-related considerations}

While suffering with an illness may help an agent to better define and clarify her values, symptoms associated with mental or physical illness also can detract from voluntarism. Roberts notes that symptoms such as ambivalence, indecisiveness, poor energy and negative thoughts may occur, and also are elements that define the diagnosis of depression. These also are consistent with physical disorders that mimic or complicate secondary depression (which result from a medical condition). ${ }^{55}$ The influence of such elements on an agent's values cannot be underemphasized. The topic is so important that I feel it should be addressed separately and in-depth, in a future chapter. Practitioners,

${ }^{55}$ Ibid., p 708. 
justifiably at times, may attribute an agent's desire to refuse treatment, or even to end her life, to conditions such as depression. Knowing whether a patient's values have been changed or if they are being distorted by depression or other factors is paramount. At this point, I will simply say that expressions of ambivalence and despondence serve as red flags of authenticity issues.

\section{Psychological, cultural and religious influences}

Psychological issues, as well as cultural and religious values, may enhance or diminish voluntarism. Many values are derived from one's cultural upbringing, which shape an agent's conception of the good. Roberts notes, "Relevant concepts of self, personhood, autonomy, and morality are shaped by the earliest of our internal and relational experiences and are revised over a lifetime." ${ }^{„ 56}$ Psychological responses to stress (such as an illness), as well as beliefs about mental illness and disease, are influenced by society, family and an individual's cultural and spiritual milieu. How one copes with illness or expresses her preferences may have an impact on the patient's decision-making.

Obviously, no man is an island; what shapes an agent's values is multifactorial, reflecting cultural, familial and experiential influences. Roberts is concerned that a practitioner's Western values may overshadow or prejudice her evaluation of the authenticity of the choices a patient makes. It is possible for practitioners to mistake a patient's preference that her children or family make medical decisions on her behalf, for example, for involuntariness. At the same time, those from communities that hold physicians in high regard may fail to express misgivings or question their doctor's

56 Ibid. 
authority, leading to inauthentic choices. Parsing out when deference to "traditional" or cultural influences is an authentically-held choice is what is at issue.

Robert's framework calls attention to important elements of authenticity, which practitioners should consider when obtaining informed consent. A teen may have the maturity to make important decisions about her health care. Conversely, a patient from a foreign nation, with limited language skills, who relies upon family to navigate the medical system, may be especially vulnerable to involuntary decisions. Before moving on to recognizing "red flags" for inauthenticity, I wish to address the issue of cultural awareness, further.

\section{Cultural awareness}

Recently, a push for cultural awareness in medicine has brought about the worry that formal informed consent requirements may impose a Western ideal of personal autonomy on those whose cultures favor a family-centered model of decision-making. In some cultures, people feel it is better not to inform elderly patients of a terminal prognosis, and believe that the family, and not the patient, should make end of life decisions. ${ }^{57}$ Some feel that providers can respect these values by asking patients if they wish to be informed about their illnesses and involved in making treatment decisions. But others believe that values expressed by such agents might not be authentic, because they are not free of "coercive formative influences." 58 Insoo Hyun encourages practitioners to look beyond the usual cultural norms of the patient's ethnic community and focus on the dynamics of the individual patient's family, as well as the circumstances surrounding her desire to relinquish her decision-making authority. Key, for Hyun, is to

${ }^{57}$ Blackhall, 1995, p 820.
${ }^{58}$ Hyun, 2002, p 15. 
ensure that the values that guide an agent's actions are authentically her own, and not "the products of wholesale indoctrination or manipulation.",59

Hyun is concerned that even an agent's ability for self-reflection may be "malformed" from indoctrination. Further, epistemic limitations prevent third parties from recognizing inauthentic values. ${ }^{60}$ The author recommends examining how an agent's values came to be acquired in order to determine whether her actions and decisions that reflect her values are truly autonomous.

Rather than viewing authenticity as the result of a person's critically reflective approval of her values, I believe we should concentrate instead on the social circumstances surrounding her acceptance of these values in the first place. To put it another way, authenticity is not a matter of what a person does, but a matter of the social context in which she comes to have her values. ${ }^{61}$

Hyun lists factors such as social restrictions on the agent and deprivations of alternatives and goods that are open to others in her social milieu. These deprivations must be 1) caused by other persons, 2) choices and goods that are reasonably available to others who are "no more able-minded and talented than she", and 3) not be justly deserved. ${ }^{62}$ In essence, the agent must be wronged by social conditions to arrive at the values she asserts.

I see problems with this proposal. First, asking a practitioner to assess "deprivations" of choices and goods smacks of paternalism. The assessment of these elements is subjective and influenced by the practitioner's own cultural background. Paternalism is what prompted the push for cultural sensitivity, in the first place. Second, and more importantly, figuring out how an agent comes to have her values (especially if

\footnotetext{
${ }^{59}$ Ibid., p 16.

${ }^{60} \mathrm{Ibid}$., p 17.

${ }^{61}$ Hyun, 2002, p 17 emphasis hers.

${ }^{62}$ Ibid., p 17.
} 
they were indoctrinated from childhood, in a different cultural milieu, possibly in a foreign country) seems daunting, not withstanding the already present epistemic difficulties. Even if one "forces [an agent] to be free," ${ }^{63}$ the agent may be ill-prepared to make medical decisions autonomously. Hyun recognizes this, as well. ${ }^{64}$ The key for my purposes is that this situation is a "red flag" for authenticity issues. I discuss other such signs in the following section.

\section{Red flags for authenticity and consent issues and their solutions}

Authenticity (or namely, its failure) often is a result of external influences, such as peer pressure. As we have seen, both external and internal forces may be at hand. I believe that practitioners can be trained to recognize signs of peer-pressure-like situations, as well as for other signs that an agent's desires are not reflective of her real self. Here I describe "red flags" that should give practitioners pause and prompt further scrutiny of a patient's choices. ${ }^{65}$ Practitioners can learn to detect the subtleties of a patient's failure to identify with her expressed desires, in order to properly seek informed consent. This issue should not be relegated to the philosophical literature, alone.

\section{Signs of pressure or influence}

Just as awareness of spousal abuse can be taught, practitioners can learn the signs of peer-pressure-like situations. Body language, such as looking to the spouse/family before answering (or allowing the family member to answer for the patient) may demonstrate hesitance on the patient's part, to express her own opinion. As noted by

\footnotetext{
${ }^{63}$ Rousseau in Hyun, 2002, p 20.

${ }^{64}$ Hyun, 2002, p 21.

${ }^{65}$ While some red flags listed may affect both capacity and authenticity, I include them here to provide a complete list of important indicators that a patient's decisions require more scrutiny.
} 
Hyun, such behavior may reflect a lifetime of indoctrination and subjugation of an agent's own preferences, as a result of cultural upbringing. The agent may defer to the family's wishes, rather than stating her own desires. Again, attempting to have insight into this situation, on the part of the practitioner, can be daunting, but is important.

The practitioner also should be aware of her own potential to overwhelm or sway her patient. The physician-patient relationship is not one of equals, and it can be intimidating for patients to question their physicians' directives. Cultural awareness, coupled with genuine concern and attempts to understand the patient's desires and their origins becomes the duty of the practitioner, when obtaining informed consent.

\section{Abrupt changes in mental state}

Confusion and disorientation most certainly demand inquiry into their cause. In the elderly a simple urinary tract infection, for example, can result in delirium and mental status changes. Changes in mood and affect, from happy to sullen or from morose to jocular should prompt an investigation, as well. The differential diagnosis includes states of delirium, dementia, medication toxicity, dehydration, infection and psychiatric disorder. Practitioners first should search for a medical cause of such changes, bearing in mind that they may indicate cause to question a patient's competence for decisionmaking.

\section{Refusal of treatment}

The simple refusal to follow a clinician's recommendation should not automatically prompt questions of a patient's capacity or of the authenticity of her choice. There are many reasons a patient might reject a given treatment plan. The patient might want a second opinion or might fear side effects of medications or the aftermath of 
treatment procedures. Perhaps the patient feels she cannot afford the suggested treatment. Sometimes, the patient simply may not like the doctor, or have been offended by the physician's bedside manner, and therefore dismiss any suggestions made by that person. The patient may have misunderstood the recommendation or may fear harm. I once had a patient who had refused to have a chemical cardiac stress test, in which a load is placed upon the heart with medications, forgoing the need to walk on a treadmill. He thought that the medications given to increase cardiac demand were given to cause a heart attack. A simple explanation of the test allowed for me to reassure him, and he went on to schedule an important diagnostic assessment.

Examining the basis for a patient's refusal is essential. At times, resolution of refusal is as simple as establishing better communication, so that the practitioner might better explain her reasons for her recommendations, but more importantly, so that the patient can describe her reasons for refusal. At times it becomes clear that a capacity evaluation is appropriate, and careful evaluation of competence should be pursued. And certainly, appreciation of the patient's values is a requirement for informed consent.

\section{Consenting to treatment that is especially invasive or risky}

Generally, practitioners attempt to recommend the least invasive, least risky treatments available. Even "routine" treatments with antibiotics, for example, can have unpleasant (though generally not life-threatening) side effects, of which both clinicians and patients should be aware. Grisso and Appelbaum recommend that experimental, intrusive or risky procedures such as bone marrow transplants (especially for genetic disorders that are not life-threatening), removal of brain tissue to control seizures and multiple organ transplants should prompt formal assessments of function to ensure 
competence. ${ }^{66}$ Psychiatric patients have been known to opt for risky treatments out of the hope that they will die, rather than benefit from the treatment. Further, patients feeling desperate for a cure might volunteer for a trial of an experimental drug or procedure when they feel they are without hope for cure by any other means. The use of formal tools for assessing capacity are described in Chapter 4 and may be useful in these situations.

\section{Change of mind}

One commonly accepted proposal to assure the authenticity of patients' choices is to examine how well new wishes cohere with prior decisions or stated preferences. But controversy exists over whether long-held beliefs better reflect the values of the agent's 'real self,' or if new preferences should be honored. An agent may change her mind about her care plan for a number of reasons. There may be a change in knowledge of the facts or a change in the facts, themselves. A patient may come to find that the medication side-effects she experiences from treatment of her condition are intolerable to her; she could not have known of this, before experiencing the treatment, however. Or a patient's condition could change; her cancer could metastasize, altering the prognosis and treatment options. The issue of authenticity versus agency, raised by Brudney and Lantos, reflects this concern. I argue that discussions with the patient, as well as with her family and friends, will provide insight into the patient's real self. Agents can authentically change their minds. They also can be overwhelmed by depression and pain, and express desires that do not emanate from their real selves. Part of the practitioner's duty is to try to discover which values reflect the real self.

${ }^{66}$ Grisso and Appelbaum, 1998, p 67. 
A change in stated desire, especially after meeting with clergy or family, should capture the attention of the practitioner. Indeed, a patient may change her mind after conferring with others, but there are situations in which the strong desires the patient expresses at the outset radically change after conferring with family — only to change back when discussed later, or when the patient is alone. An important red flag is when the family members refuse to allow the practitioner to be alone with the patient, in order to prevent discussion that might run counter to their preferred plan. The practitioner should explain that it is essential to confer with the patient privately, as part of the physician-patient relationship. When such situations arise, it is the practitioner's duty to probe deeper into the situation. As discussed previously, cultural awareness is an important component of this process. Of course, the patient's preferences cannot be summarily dismissed. But issues of inauthenticity require greater attention by practitioners, as well as deeper reflection, on the patient's part.

\section{Real-world authenticity}

Some are concerned with how it might be possible for people to have insight into another's real self views. They question whether outsiders (or even the agent, herself) can have access to the real self. We should acknowledge that there simply may be a limit to how good or well-justified our determination of an agent's real self views can be in an actual medical setting. Limitations in time, financial resources and epistemic insight are genuine considerations. In addition, there may be no clear way to establish how much a given condition, at present, is altering the agent's self. But to adopt this attitude is immediately unhelpful, as the simple fact remains that despite the problem of ineffability, the practical matter of assuring and respecting autonomy remains. 
As I have mentioned, questioning a patient's values has been used as a means to question a patient's competence. And as noted in the preceding section, a change in values and a change of mind are just two of the red flags that can point to inauthenticity. But red flags only identify the need for further investigation; practitioners should not automatically discount a patient's expressed preferences. Paternalism arises when those with such concerns assume that a new choice or a refusal of care is not in keeping with the patient's authentically-held desires, without taking care to investigate. Practitioners are duty-bound to incorporate an assessment of values in the course of obtaining informed consent and to avoid misusing questions of authenticity as a means to undermine a patient's autonomy.

\section{Conclusion}

I propose that informed consent consist not only of an assessment of the patient's intellectual functioning and insight, but of her system of values. Simply assuming that a patient agrees with the practitioner is bound to fail. Further, dismissing any patient who disagrees with the practitioner as crazy or incompetent is irresponsible, as well. However, even practitioners who endeavor to explore a patient's values may stumble. The distinction between agency and authenticity is an important one; appeal to "agency" should not allow a practitioner to stand by as her patient acts against her own best interests or values. Additionally, appeal to "authenticity" should not allow for the dismissal of new choices and changes of mind.

I have noted that many of the elements that can impair capacity also may influence an agent's authenticity and system of values. While some disagree about the nature of the real self, its organization and its accessibility, it nevertheless plays an 
important role in the development of an agent's values. Some hope that some "test" might be developed to demonstrate the authenticity of an agent's choices. Ideally, this would be so, but from a practical standpoint, practitioners must develop ways to evaluate an agent's choices, based upon more indirect methods. These involve (potentially) lengthy conversations with the patient and her family. It requires the practitioner to look for clues as to the values that motivate the agent, as well as for red flags that the agent might be acting against her real self desires. A change of mind, body language that conveys acquiescence, and signs of depression such as low self-esteem and hopelessness warrant further investigation on the practitioner's part.

My goal is to provide a philosophically sound, yet practical account of informed consent to inform these situations. Rigorous Informed Consent requires a thorough examination of the patient's values, in addition to assessment of her decision-making capacities. But despite these efforts, we may never ensure perfect patient autonomy. What we must find is a way for agents to be "autonomous enough" for making decisions. In my third chapter, I describe an account known as "substantial autonomy" and explain how it can address the flaws with current informed consent practice. 


\section{CHAPTER 3: SUBSTANTIAL AUTONOMY AND THRESHOLD COMPETENCE}

\section{Introduction}

As discussed in Chapter 1, the most rigorous conceivable standard is not always the most appropriate standard for competence. "Full autonomy" or "ideal autonomy" is not always possible, and perhaps is possible only on rare occasion. Moreover, it is not always necessary to attain. Also, we recognize that patients in situations such as lifethreatening emergencies (when implied consent applies) or when treatment risk is quite low (as in the case of an obvious fracture) need not meet the same standard as when undergoing experimental therapies or requesting PAS. We need a more flexible approach. I have proposed informed consent coding, which can allow for different levels of capacity for competence, varying by case. But this system pertains only to evaluations of capacity. As I have discussed previously in Chapter 2, a narrow view of competence looks only at questions of capacity, while a broader view incorporates being informed and authenticity. The informed consent process is designed to operationalize respect for autonomy, so all of these elements should be considered. This means that evaluating capacity alone is not enough. We should consider the other elements that constitute informed consent, as well as what makes an agent sufficiently competent to make medical decisions. I wish to delve into this in greater detail. In this chapter I define criteria for autonomy and competence in ordinary agents. I review a number of views on autonomy and competence, assess those proposals, and offer my own approach. I introduce the concepts of Substantial Autonomy and Threshold Competence as essential to the assessment not only of capacity, but of competence. My hope is to improve the informed consent process in medical practice, through these measures. 


\section{Views of autonomy and competence}

Autonomy requires that an agent have capacity and act authentically, based upon the information presented to her. But in ordinary life, people whom we consider autonomous make choices without meeting the standards for being "fully" or "ideally" autonomous. For example, an agent might decide to purchase a car without being ideally informed about the mechanical workings of automobiles; she simply might like the color, style or brand name. External peer pressure from one's family may influence an agent to have a large, religious wedding, when she would prefer a small civil ceremony. As discussed in Chapter 2, agents may not be fully aware of internal factors that influence their real selves, subconsciously. And agents who lack insight and even high intelligence nevertheless manage their daily lives to a degree we all find acceptable in choosing schools for their children, investing in the stock market and purchasing real estate, for example.

We also recognize that agents may not be fully autonomous at a given time, for certain types of decisions. Some situations may only be temporary, as when intoxicated. (Think of the number of marriage proposals and regretted tattoos that have occurred during moments of inebriation.) Other situations may always require a high degree of autonomy — to go skydiving or to join the military, let's say. While ideal autonomy is not required for autonomous choice, the degree of autonomy required depends upon the significance of the choice. Matters of medical decision-making are given more gravity because such choices can have a great effect on the health, welfare and overall good of the individual. It is important that we develop some criteria for autonomy that ordinary agents can meet that are nonetheless appropriately rigorous for such important situations. 
In their work, Beauchamp and Childress emphasize this idea that we should not expect or require ideal autonomy in medical decision-making:

An appropriate test of the adequacy of any theory of autonomy is whether it coheres with the moral requirement that we respect the ways in which we govern our lives, such as the ways we take care of our health and take care of our children, as well as our everyday choices, such as opening bank accounts, purchasing goods in stores, and authorizing repair of an automobile.... No theory of autonomy is acceptable if it presents an ideal beyond the reach of normal agents and choosers. ${ }^{67}$

Autonomous actions, for Beauchamp and Childress, need only a "substantial degree of understanding and freedom from constraint, not a full understanding or complete absence of influence." 68 They believe that we can respect the autonomy of "normal choosers" in nonideal conditions who act (1) intentionally, (2) with understanding and (3) without controlling influences that determine their action. While acts are either intentional or nonintentional, actions can be autonomous by degrees, since the latter two conditions can be satisfied to different degrees. They acknowledge that in the practical world, people's actions are rarely, if ever, fully autonomous; decisions of great consequence, therefore, must be substantially autonomous, rather than fully autonomous. ${ }^{69}$ The line between these may appear arbitrary, they admit, but thresholds for autonomy marking "substantially autonomous decisions" can be found. ${ }^{70}$ When the criteria are met for being autonomous in a particular context, agents possess what I will term Substantial Autonomy.

The concept of meeting certain thresholds for autonomy has practical appeal. But developing the correct view requires further thought. There are multiple factors to

${ }^{67}$ Beauchamp and Childress 2009, p 101.

${ }^{68}$ Ibid.

${ }^{69}$ Ibid., pp 101-2, emphasis theirs.

${ }^{70}$ Ibid., p 102. 
consider in establishing such thresholds and in applying standards by which to measure patient autonomy. Here I outline a number of possible views of autonomy, discuss their implications, the views of other philosophers, and provide what I believe is the correct view.

\section{Thresholds for autonomy}

With regard to thresholds, we could vary the level of autonomy required for decision-making depending upon the question at hand, as I advocate, or it could be fixed across all cases. If it were fixed, agents would be required to meet a single level of autonomy, no matter how clear the choice and no matter the consequences. As I alluded to in Chapter 1, the trouble with this approach is that there are times when lower standards may be appropriate, as in the case of an obvious fracture. Furthermore, setting a single requirement for all situations would have the potential to set a standard that would be inappropriately high in some cases or ridiculously low across the board. Normal choosers might never be able to demonstrate sufficient autonomy to opt for an organ transplant, for example; those of borderline intellectual functioning could be allowed to consent to experimental drug therapy, without comprehension of the nature of the study.

Rather, varying the levels of autonomy, depending on the case, allows us to set an appropriate threshold for autonomy for a given situation, above which agents "pass the test" and below which agents cannot provide consent. We can accommodate clinical decisions in which a lower expectation of autonomy is acceptable, such as the angulated fracture with clear need for treatment, while setting a higher threshold for those that 
require greater insight into the potential harms and benefits, such as experimental therapies.

Some argue that the informed consent process is not merely a form of soft paternalism. They believe that a single standard across cases would be considered soft paternalism, but a varying standard slips toward hard paternalism. Requiring a higher standard for more risk, for example, allows others to step in and act paternalistically, putting an agent's good above her autonomy. Essentially, we are making the decision for the agent, and this is hard paternalism.

I argue that setting too high a bar would be even more paternalistic, as some agents - even normal choosers — might not be able to meet such a high level of competence. Conversely, setting too low a bar might let many people make terrible and dangerous decisions. While I believe that competent people should be allowed to make what others might consider to be terrible decisions, this should not become commonplace, and I fear that a rigid threshold for autonomy threatens to do this. Those who disagree with me may be willing to bite the bullet for a high or low bar, but I believe the variable threshold is superior.

Second, I endorse sliding scales for autonomy because it is possible for a given agent at a given time to be competent to make one type medical decision, but not another. An example is provided by Beauchamp and Childress.

If a serious risk such as death is present, then we need a correspondingly stringent standard of competence; if a low or insignificant risk is present, then we may use a relaxed or lower standard of competence. Thus, the same person-a child, for example - might be competent to decide whether to take a tranquilizer but incompetent to decide whether to authorize surgery. ${ }^{71}$

${ }^{71}$ Ibid., p 116. 
Were a single threshold applied across cases, the child in this example might be allowed to authorize surgery, even though she lacks the ability to comprehend the complexity of the matters at hand. This cannot be what those who object to my conception intend.

The most likely (and feasible) dimension of autonomy to vary is capacity, but I do not wish to exclude the possibility that authenticity can vary, as well. ${ }^{72}$ I believe that there must be a threshold to be "authentic enough," just as there is for capacity. Surely agents bring with them varying degrees of authenticity, which may depend not only on them as individuals, but on the matter in question. (They may feel strongly about some issues and not about others.) It may be that, often, both capacity and authenticity go hand-in-hand. That is, weightier decisions requiring higher capacity may also demand clear accord with one's values. Likewise, consenting to the repair of the angulated fracture not only may require a low-level of understanding, but the strength of conviction to one's values may not be especially important. On the other hand, for a Jehovah's Witness to refuse a blood transfusion may require a lower capacity to understand its consequences (death without blood replacement), but a higher measure of authenticity (conviction to one's religious beliefs.) Given the concern practitioners have regarding the competence of patients requesting PAS, for example, I think it is best to place a high demand of authenticity on such choices, while requiring a lower threshold for authenticity for less weighty issues.

\footnotetext{
${ }^{72}$ While the amount or detail of information might also be adjusted given the circumstances, generally speaking, the facts of the matter are fixed. For this reason, I do not pursue this avenue of discussion, here, but it could be argued that matters of greater complexity, by the very nature of that complexity, automatically demand a greater amount of information or information of greater depth/detail.
} 


\section{Measuring autonomy}

We accept that there should be different levels of autonomy for different situations. Next, we must examine how autonomy should be measured. The process of obtaining informed consent is designed to operationalize respect for autonomy. In doing so, we look for evidence to establish an agent's competence to decide the matter at hand. I argue that the components of informed consent (capacity and authenticity) are ideally suited to provide such evidence. ${ }^{73}$

Joel Feinberg holds a similar view of autonomy, incorporating both capacity and voluntariness ${ }^{74}$ into his assessment. He proposes that the greater the risk, the greater the threshold level of capacity to which the agent should be held. Voluntariness, too, is a variable concept for Feinberg, with higher or lower cut-off points on a common scale. As with evaluations of capacity, these are determined by the nature of the circumstance, interests at stake, and the moral or legal purpose to be served. ${ }^{75} \mathrm{He}$ introduces Aristotle's 5-point model of a perfectly voluntary choice, to point out that it is “... so elevated a test of voluntariness that relatively few acts could satisfy it." ${ }^{.76}$ Aristotle's model requires: 1) The chooser is "competent"; 2) He does not choose under coercion or duress; 3) He does

${ }^{73}$ Beauchamp and Childress strongly emphasize placing levels of evidence on a sliding scale according to risk, rather than competence itself as a means to avoid "blend[ing] a decision's complexity or difficulty with the risk at stake." (Beauchamp and Childress, 2009, p 117) However, their argument is confusing, as some may interpret them to say that competence should remain fixed (across cases), while evidence varies. I do not interpret them in this way. Using competence (the ability to perform a task) as a means to verify autonomy (self-governance) leads directly to the idea of examining the elements of competence (being informed, having capacity and acting authentically) to ensure that an agent meets a given threshold for autonomy. I think their emphasis on thresholds of autonomy for different cases bears this out.

${ }^{74}$ Recall, I endorse the use of the term "authenticity," but I am using Feinberg's language, here, for consistency.

${ }_{76}^{75}$ Feinberg, 1986, p 117.

${ }^{76}$ Ibid., p 114. 
not choose because of more subtle manipulation; 4) He does not choose because of ignorance or mistaken belief; and 5) He does not choose in circumstances that are temporarily distorting. ${ }^{77}$ Feinberg, instead, asserts that common sense suggests the following rules of thumb to permit certain types of conduct: the more risky the conduct, or the more irrevocable the risked harm, the greater the degree of voluntariness required. $^{78}$

\section{Risk, consequences, and complexity}

Many philosophers agree with a threshold view of autonomy and choose to evaluate competence based upon "capability for a task," or competence. But we have already gotten ahead of ourselves. If we are to set thresholds, they must be based upon something. I argue that what determines if the threshold should be higher or lower depends upon the risk of harm of a choice (its potentially dire consequences), its potential benefits, and the complexity of the decision to be made. ${ }^{79}$ Recall that when an agent weighs her options, she examines the potential consequences of that choice, but she also must weight the risk of refusal or (to increase the complexity of the situation) consideration of an alternative treatment. Additionally, the elements of the choice may be complex, as in the case of a research study with multiple treatments, variable controls, and elements of blinding (of research participants and practitioners).

It would seem that decisions that are risky (have potentially dire consequences) require great decisional capacity--but not necessarily. Beauchamp and Childress make an interesting point about risk:

\footnotetext{
${ }^{77}$ Ibid., p 118.

${ }^{78}$ Ibid., pp 118-120.

${ }^{79}$ We should not only consider risk of harm. A choice can be so potentially beneficial that it is a "no-brainer".
} 
No basis exists for believing that risky decisions require more ability at decision making than less risky decisions. To the contrary, many nonrisky decisions appear to require more ability at decision making than many risky decisions. ${ }^{80}$

This seems compelling. A risky surgical procedure to remove a mass growing close to the brainstem could be the only course of action, versus certain death. And a situation where true clinical equipoise exists may not pose much of a risk, but may make it difficult for a patient to choose between two good options. This means that a high-risk procedure should not automatically require a high level of autonomy for decisionmaking.

We can agree that when a choice seems clear, a lower threshold of competence is required, while a more complicated situation requires greater insight. Comprehending a research protocol with double blinding and multiple experimental interventions might require greater competence than deciding to start taking blood pressure medication that has been prescribed safely for more than 50 years. But one should be careful to describe where the complexity lies. It could lie in the complexity of the procedure or in the complexity of the choice. I mean for the threshold to be based upon the choice being made by the agent. The surgery to repair an open (sticking out of the skin) ankle fracture-dislocation might require a prolonged and complicated surgery involving the use of multiple plates and screws, but the choice to have the surgery done could be an easy one, given the likelihood of morbidity without the surgery. The complexity, here, is not in making the choice - the patient's role--but in performing the procedure- the physician's role.

${ }^{80}$ Beauchamp and Childress, 2009, p 117. 
This is not to say that the complexity of the surgeon's task does not affect the risk (and therefore the threshold for competence) of a procedure. The surgery's complexity may have an impact on the potential outcome of the case (the function of the ankle may not be restored to normal, for example). This is a consideration of the consequences of the decision (the risk of the procedure), that of having the surgery with a resulting imperfect ankle, or not having the surgery, with the potential for worse disability such as amputation, infection or even death. The complexity of the surgeon's task may bump the risk level of the decision, compared to a simple surgical repair, but the patient is still faced with a choice between surgery or gangrene, so her option is clear.

As I have mentioned, assigning a threshold may be more difficult in situations in which there is clinical equipoise. Imagine a case where a patient has end-stage cancer and has exhausted her treatment options. She is offered the opportunity to participate in a trial of a novel therapy, whose likelihood of success is unknown. If the two choices pose equal risk of harm (and benefit), at what level should the threshold for autonomy be set? Perhaps it should be low, since the patient is likely to die with current treatment (since current treatments are futile) and may be as likely to die with the experimental therapy. Or perhaps the bar should be higher, since the treatment is experimental and the potential risk of harm is unknown. I am more likely to set a low bar, given the fact that the patient has a poor prognosis with either therapy.

But consider another situation in which there are two procedures where the risk of harm is identical, but in one, the patient needs a high level of insight to comprehend the proposed treatment, and in the other, the procedure is easily understood. It would seem that making this choice would require a greater level of insight and comprehension, to 
parse out the differences between the two. Given that the risk is truly equal, however, one could argue that a flip of a coin is all that is required to make such a choice, and if this is the case, a low bar could be set, since coin flipping, as it were, provides little intellectual exercise.

\section{A discussion of autonomy views}

Now I would like to describe and critique the views of other philosophers on matters of autonomy. Many of them agree that some threshold should be established for autonomous action and that assessments of competence answer this question.

Beauchamp and Childress advocate a fixed level of competence, above which threshold agents are treated as equally competent, and below which agents are treated as equally incompetent, for a given purpose. ${ }^{81}$ The threshold level for each situation may differ, but "[f]or practical and policy reasons, we need threshold levels below which a person with a certain level of abilities for a particular task is incompetent. ${ }^{, 82}$ Where to draw the line depends upon the particular tasks involved. ${ }^{83}$

Joel Feinberg agrees with this threshold view. He points out that a "threshold conception of natural competence" is used to stipulate the necessary and sufficient conditions for individual self-government. He notes:

It is the threshold conception of natural competence - minimal relevant capability for a task - that is used in stipulations of necessary and sufficient conditions for the sovereign right of self-government ascribed to individuals. Some competent persons are no doubt more richly endowed with intelligence, judgment, and other relevant capabilities than others, but above the appropriate threshold they are deemed no more competent (qualified) than the others at the "task" of living their own lives according to their own values as they choose." 84

\footnotetext{
${ }^{81}$ Ibid., p 114.

${ }^{82}$ Ibid., pp 113-4, emphasis theirs.

${ }^{83}$ Ibid., , p 114.

${ }^{84}$ Feinberg, 1986, p 30.
} 
Gerald Dworkin opts for the narrow interpretation of competence, but agrees with thresholds for autonomy. He notes that while persons of normal intelligence and rationality may have the capacity to reflect upon their lives and shape them, it is not the case that all persons have this capacity equally. For this reason, he believes that capacity of this type has a significant threshold. An agent who possesses this capacity above some particular level is autonomous. ${ }^{85}$

Allen Buchanan and Dan Brock also believe that competence varies with the choice to be made, based upon the consequences of that decision.

Because the appropriate level of competence properly required for a particular decision must be adjusted to the consequences of acting on that decision, no single standard of decision-making competence is adequate. Instead, the level of competence appropriately required for decision-making varies along a full range from low/minimum to high/maximal. ${ }^{86}$

They argue that consenting to a low-risk procedure, such as a lumbar puncture to rule out meningitis, requires a lower level of competence than would be required to refuse an appendectomy; ${ }^{87}$ the risk of death due to infection by refusing this simple, but important procedure merits a much higher level of competence to make sure the patient is making a reasoned decision.

I find this line of reasoning compelling, as it is consistent with the informed consent coding system I have proposed. A procedure such as a lumbar puncture presents little harm, and so should require a lower threshold of competence. Additionally, it incorporates an important factor with respect to treatment refusal. That is, refusing a

${ }^{85}$ Dworkin, 1988, pp 31-2.

${ }^{86}$ Buchanan and Brock, 1989, p 53.

${ }^{87}$ Ibid. 
simple appendectomy should require a higher level of competence than consenting to it, due to the potentially dire consequences of its refusal.

Such a view is not unprecedented. Beauchamp and Childress note that a higher standard of evidence for competence is required in making than in invoking advance directives. ${ }^{88}$ Further, The National Bioethics Advisory Commission recommends a higher standard to consent to participate in most research than to object to participation. ${ }^{89}$

Really, two things are happening when we are making decisions. First, when we speak of "making a choice," we are choosing between (at least) two options. Each option has its own level of risk. In situations where the choice is quite clear (the "no-brainer" situation) normatively there may be only one "choice" (better option), but descriptively, there remain two options. What makes a "no-brainer" so clear is that the risk of one option far outweighs that of the other. So the second thing that happens is we weigh each option, independently. The level of competence is not tied to the choice, itself, but to the elements (the options) of that choice. In medicine, the preferred course of action becomes the standard of care, such as appendectomy for acute appendicitis. Sometimes, when there is clinical equipoise, the science is less clear and the options are more equal in their degree of risk. But there are always two options with every choice, with differing levels of potential risk, for each option.

\section{Evidence for competence}

With capacity and authenticity as the metrics, our final task is to determine what levels of evidence must be met for competence, for each case. One way to evaluate

\footnotetext{
${ }^{88}$ Beauchamp and Childress, 2009, p 117.

${ }^{89}$ Report and Recommendations of the National Bioethics Advisory Commission, 1998, p 58.
} 
capacity is with standardized tests. Several examples of tests of capacity that already are utilized are the Mini Mental Status Exam (MMSE) ${ }^{90}$ the Hopkins Competency Assessment Test (HCAT), ${ }^{91}$ the MacArthur Treatment Competence Research Instrument (MacCAT-T),${ }^{92}$ the Aid to Capacity Evaluation (ACE), ${ }^{93}$ and the Assessment of Older Adults with Diminished Capacity. ${ }^{94}$

My first suggestion is to take advantage of these types of tests to develop the informed consent coding system I have described. With the model I have put forth, all medical procedures are coded on a severity scale from 1-10, with each level of the scale associated with a given demand of rationality and comprehension. For some decisions such as a lumbar puncture, mere expressions of a choice can suffice. For questions of higher risk such as assisted suicide, however, a high degree of insight and understanding is warranted. The highest level of evidence and the strictest test of capacity are required to establish that an agent's treatment decision is not made as the result of a "defeater" of capacity. Agents must meet the level indicated by the coding system to be "substantially autonomous" for a given treatment or procedure. When agents meet the criteria for capacity, as defined by such tests, practitioners can feel assured, to a good degree, that the agent is competent, barring any other incapacitating circumstances such as inauthenticity. ${ }^{95}$

\footnotetext{
${ }^{90}$ Folstein, 1975.

91 Janofsky, 1992.

${ }^{92}$ Grisso, et.al., 1997.

${ }^{93}$ Etchells.
}

94 Diagnostic and Statistical Manual of Mental Disorders, Fifth Edition, 2013.

${ }^{95}$ Note that such capacity may involve both the ability to assess consequences/risk and comprehension (complexity) of the choice at hand. 
It is important to point out, once again, that even if the strictest test of capacity is applied, there nevertheless will be something missing from the informed consent process, if we stop here. My second suggestion is that we must look for authenticity. Ascertaining the degree of patient insight requires investigation into her perception of her self and her values. The physician must invest time with this process. This is what is required of Rigorous Informed Consent and regard for authenticity. In the following section, I will explain what factors should be taken into account in applying Substantial Autonomy. I will provide a set of elements that should be employed in the decisionmaking process, in order to address the flaws that I have identified in prior chapters, and I will introduce the new concept of Threshold Competence.

\section{An addition to Substantial Autonomy: Threshold Competence}

Elements such as excruciating pain may affect both authenticity and capacity. Undoubtedly, there are some patients with depression who cannot provide proper consent. Even without defeaters of capacity, there are few ideal choosers in the world. I argue that normal choosers need only meet a minimum requirement for competence in order to make decisions in their daily lives - even when these decisions pertain to medical treatment. But I also endorse the need for there to be a higher standard of competence when decisions involve the potential for greater risk to the patient or in the case of end-of-life decisions.

This means that changes of mind, even over a short period of time, may be honored when the agent demonstrates a high level of insight into her condition and its prognosis. Pain and, I will argue, depression, when appropriately addressed, do not 
necessarily interfere with autonomy. ${ }^{96}$ The key, then, is to establish when an individual has what I term Threshold Competence, and how this competence is defined, for a given decision.

When an agent meets the given criteria for Substantial Autonomy for a given situation, she possesses what I call Threshold Competence for that decision. Threshold Competence varies for the particular situation at hand. As discussed before, some choices may be clear and require a minimal level of capacity, while others might have potentially serious outcomes, requiring a greater level. When an agent possesses Threshold Competence, she has the minimal, particular competence required to make a decision for a particular situation. I am providing an official term for that level of evidence needed to indicate that an agent is Substantially Autonomous for a given situation. I make a distinction between Threshold Competence (a kind of competence) and "a threshold of competence" (a measure of competence). When the evidence meets that level, the patient has Threshold Competence.

If we opt to utilize informed consent coding, an agent would have to meet the criteria for capacity set forth for a given treatment or procedure, as indicated by the coding system. The agent would need to demonstrate insight into her condition. Incorporating other elements of informed consent, the patient also would need to be appropriately informed and be acting authentically such that her decision reflects her values. If all of these criteria were met, she would be said to have Substantial Autonomy to make a given decision and thus Threshold Competence.

\footnotetext{
${ }^{96}$ I give full attention to this argument in Chapter 4.
} 


\section{Applying Substantial Autonomy and Threshold Competence}

Remember, no matter what approach to capacity we feel is appropriate, even with consent coding in place, consideration of the agent's real self views is paramount.

Although Substantial Autonomy explains how different situations warrant different levels of evidence for competence, it does not provide a measuring tool or coding metric for authenticity. Yet looking for authenticity is essential to guarantee that an agent's decisions reflect her real self values. Rigorous Informed Consent requires that the practitioner assess not only a patient's capacity, but her values as well. And a patient cannot possess Threshold Competence if she acts inauthentically.

The assessment of values and authenticity may present the greatest challenge to our desire to operationalize respect for autonomy through the informed consent process. When practitioners go from demanding "full" autonomy to Substantial Autonomy, there may be disagreement among them about whether evidence for a given agent's competence is sufficient for a given circumstance. Practitioners could agree on the facts of the matter (and even agree with an informed consent coding number) without agreeing that an agent meets criteria for Substantial Autonomy, because of the other elements involved. The epistemic limitations regarding insight into an agent's authentic self cannot be avoided, but we should not abandon this aspect of the process.

I understand that some philosophers may be purists about morality and autonomy, feeling that agents must meet the highest standard. But not all philosophers agree. ${ }^{97}$ There is a danger to holding agents to a Platonic ideal, yet those in the medical field should not reject all philosophy on the matter, either. Gaining greater philosophical

${ }^{97}$ One oft-cited example is J. O. Urmson, who felt the demands of traditional moral theories were unreasonable for ordinary people to attain. Urmson, J.O., 1958, pp 193-9. 
insight informs real-world decision-making. Developing a viable autonomy view will assist medical practitioners when they are faced with difficult ethical decisions. I wish to assure readers that this is not a lost cause. We simply need to see how Threshold Competence might be applied both theoretically and practically.

In Chapter 1, I described the Expedience Problem and the Least Agreement Problem. In the former, the desire for expedience wins out over respect for patient autonomy. The practitioner fails to probe the patient's understanding of the matter at hand. In the latter, the practitioner selects the test that best fits with her bias and assumptions in order to have the desired outcome that she thinks is most appropriate, without risking patient objection. As I have explained, previously, I do not think that these problems result from malicious intentions on the part of medical practitioners. They simply reflect an all-too-common human foible, to assume that all parties are in agreement so long as no one says otherwise. Physicians, nurses and other medical professionals are pressed for time. Indeed, there may be situations in which a comprehensive informed consent process must be deferred, when emergent conditions are at hand. Nevertheless, complacency should not be the norm. It is here that employing a sliding scale for standards of evidence is appropriate. Certain types of decisions, such as forgoing treatment or requesting assisted suicide, should merit a greater degree of certainty regarding an agent's values and capacity for decision-making. Proper investment of time in communicating with patients is essential. More "mundane" treatment options may warrant less scrutiny, in the interest of the patient's wellbeing. But at no time should complacency be accepted, and at no time should the search for authenticity be given short shrift. 
For all of these cases, the process of Rigorous Informed Consent should be required, and this can overcome other problems I describe, such as the Defeater Problem and the False Consent Problem. The Defeater Problem occurs when providers "jump to conclusions" and override the wishes of the patient, due to circumstances such as pain or depression, conditions which can impair competence, but do not necessarily do so. The False Consent Problem is "jumping to the opposite conclusion," where practitioners overlook true defeaters of capacity. Practitioners should be compelled to explain procedures and treatment plans above the minimal requirements on a consent form. Further, they should not allow patients who lack proper understanding for a given procedure to consent to it. This is what is involved in meeting Threshold Competence for a given procedure. In discussing the proposed treatment plan, the practitioner has the opportunity to get to know her patient and understand her real self values.

The final impediments to the discussion of a patient's values and preferences are both a lack of time to accomplish this during the physician-patient encounter, and money to pay providers to have these conversations. Physicians in the United States are reimbursed based upon a coding system known as the International Statistical Classification of Diseases and Related Health Problems (ICD-10). Different types of patient encounters and procedures receive a different coding number, and reimbursement is based upon this number. Only recently has the United States government made discussion of end-of-life care, discussion of advance directives and resuscitation status subject to reimbursement through Medicare and Medicaid. Up to this point, busy physicians have lacked incentive to have such discussions with their patients, even when they would like to do so. When demands are placed upon physicians to see one patient 
every 15 minutes in their offices, care that is not subject to reimbursement is omitted. As disappointing as it might be, lack of reimbursement is a real-world obstacle to having meaningful conversations, which includes properly obtaining informed consent. I have introduced the idea of employing informed consent specialists to assist in the informed consent process. This, too, has financial implications. But, if we are truly concerned about respecting autonomy, we must choose to compensate physicians and others for having these conversations. It may be less expensive not to talk to patients and to accept the status quo, but this is at the expense of patient autonomy.

\section{The importance of respect for autonomy}

Before concluding this chapter, I wish to address an important topic for future discussion. My hope is to provide suggestions for improving the informed consent process in medical practice. But my motivation pertains to a specific patient population. As I have noted, most patients do fine with the consent process as it stands, as most patients possess sufficient capacity for decision-making, without duress, in keeping with their system of values. What troubles me are the exceptional cases, where agents wish to reject the treatment plan outlined by their practitioners. Often, their motives and even their sanity are questioned. ${ }^{98}$ I have noted problems with the informed consent process as it stands, where paternalism can sneak in, even under the benevolence of the health care providers. If this can happen for the mundane cases, what can we expect for the exceptional ones?

Readers may wonder if measures such as Rigorous Informed Consent, informed consent coding and Threshold Competence truly are necessary. If practitioners were to

${ }^{98}$ Burnell, 1995, p 510. 
focus upon the flaws I have raised and endeavor to do better, wouldn't this be sufficient to ensure respect for autonomy, in the exceptional cases? I am skeptical, for the following reason. At present, when practitioners feel uneasy about an ethical situation, it is common for them to obtain a psychiatric and/or an ethics consultation to ensure the competence of the patient. In theory, psychiatrists should be most adept at evaluating a patient's mental health, including evidence of psychosis and depression. Similarly, those serving on ethics committees should have the greatest experience with deliberating about ethical quandaries, including requests to refuse care or for physician assisted suicide. However, those serving in these roles carry with them their own values and prejudices about questions of competence. For example, those who believe that life should be preserved above all else (even in those who are comatose or suffering intractable pain), may "vote" to keep patients alive, despite requests (in advance directives or from the patients, themselves) to end their lives. Such decisions can be made under the auspices of questioning patient competence. Without the types of measures I recommend, I fear, patients may continue to suffer with conditions that are arguably worse than death, itself.

\section{Concluding thoughts}

What I have outlined is a proposal for obtaining informed consent by establishing that an agent possesses Threshold Competence. This concept results directly from the idea of Substantial Autonomy, with the understanding that each situation warrants its own threshold for competence, and each its own level of evidence for competence. Situations involving greater potential patient harm, experimental therapies, forgoing lifeextending treatments, or requesting assisted suicide clearly warrant greater scrutiny and a more rigorous approach to informed consent. A system of informed consent coding, 
much like the ICD-10 procedure codes, can be implemented to assist in establishing that an agent possesses Threshold Competence for a given treatment. But no matter which approach is employed, practitioners are duty-bound to ensure that patients make an authentic choice. Failure to do so precludes proper obtaining of informed consent. In my final chapter, I will provide greater detail of the types of assessments that may be utilized in the informed consent process and address the exceptional cases that motivate my project. 


\section{Introduction}

\section{CHAPTER 4: EXCEPTIONAL CASES}

The informed consent process was developed with respect for patient autonomy in mind. In the chapters leading to this point, I have described problems I see with the informed consent process in practice, and with evaluation of capacity in particular. The process has become routine - so routine, in fact, that practitioners have become complacent in their duties. As I have noted, most patients do fine with the consent process as it stands, as most patients possess sufficient capacity for decision-making, without duress, in keeping with their system of values. There are times, however, when the wishes of patients who arguably have capacity are challenged and their competence questioned. This is because while for traditional medical treatment, patients are presumed to possess capacity for consent, in exceptional cases, the burden of proof is shifted onto the patient instead. Recall, the exceptional cases are those in which patients may wish to forgo care or refuse life-prolonging treatment - even to request physicianassisted suicide (PAS). Those enduring pain and depression receive my attention because such cases have been used as examples in the literature and in practice for overriding patient preferences. ${ }^{99}$ Often, patients' motives and even their sanity have been questioned. The reason for this is that in cases of suicidal ideation or attempted suicide, the very fact that a patient wants to end her life is provided as a reason to doubt her capacity. ${ }^{100}$ This line of reasoning has been extended to anyone wishing to forgo lifeextending medical treatment; that one would wish for a shorter life (of any quality) calls

${ }^{99}$ Ibid.

100 Ibid. 
into question one's competence. In these situations, preserving a patient's life is put before respect for autonomy, in a paternalistic fashion.

Recall, with soft paternalism, practitioners impose upon patient autonomy to protect a patient from possible harms when they believe her decisions are not informed or are not voluntary. In hard paternalism, a patient's autonomous choices are overridden, even when her competence is intact. ${ }^{101}$ We must use caution for the exceptional cases, as the temptation is to employ paternalism in situations where it does not apply. These are the cases where a patient makes clear requests (to end treatment, for example) that may run counter to the practitioner's advice. And while hospice and palliative care may apply for some, such as those riddled with metastatic disease, for those with more than six months to live, a slow course of deteriorating health and disability may run counter to their view of an acceptable end-of-life experience. These patients are not apathetic, but rather, engaged in their care and emphatic in their requests. For these patients, paternalism is not benign, that is, normatively acceptable, at all.

Here I provide factual background regarding depression as it pertains to suicide risk, medical decision-making, and end-of-life preferences. I will demonstrate that some people with depression nevertheless are competent to make medical decisions in four ways. First, I discuss studies showing that suicide is no more prevalent in the terminally ill than in the general population. Second, I look to studies of depressed patients which demonstrate that both their capacity for decision-making and appreciation of their situation are intact. Third, I show that preferences for the end of life amongst depressed patients are similar to those without depression. Finally, I look to diachronic evidence

${ }^{101}$ Lo, 2013, p 35 . 
demonstrating the persistence of patients' preferences over time, even after treatment for depression. I conclude with a description of assessment tools of capacity, I explain how Threshold Competence can be applied to depressed patients, and I describe the role of the practitioner in evaluating informed consent.

\section{The diagnosis of depression}

Depression comes in many forms, which can be difficult to differentiate from one another. The diagnostic criteria include depressed mood, diminished interest in activities, weight loss or gain, problems with sleep, psychomotor agitation or retardation, fatigue, feelings of worthlessness, difficulty concentrating, and recurrent thoughts of death. (Not all of these criteria need be present. ${ }^{102}$ Major Depressive Disorder (MDD) and Bipolar Affective Disorder are only two of many mood disorders that comprise the Axis I definitions of clinical disorders, which include all psychological diagnostic categories except mental retardation and personality disorders. Medical conditions can be life stressors, which can bring on an adjustment disorder or an episode of major depression. Mood Disorder Due to a General Medical Condition also falls under the subset of Mood Disorders. Practitioners examine the pervasiveness of the the depressive picture and the number and quality of depressive symptoms in making a diagnosis. ${ }^{103}$ Differentiating MDD from other forms of depression largely focuses on duration of symptoms and the inability to explain the condition by other means. Practitioners are encouraged to identify a temporal association between the onset, exacerbation or remission of the general medical condition and that of the disturbance of mood in their assessments. ${ }^{104}$

${ }^{102}$ Diagnostic and Statistical Manual of Mental Disorders, Fifth Edition, 2013, pp 160-1. 103 Ibid., p 183.

${ }^{104}$ Ibid., p 181. 
Adding to the difficulty of diagnosing the type of depression at hand is the fact that many depressive symptoms mimic those of a number of medical disorders. Of note, several conditions involving neuroanatomical disorder demonstrate clear associations with depressive disorder due to another medical condition, including stroke, Huntington's disease, Parkinson's disease and traumatic brain injury. ${ }^{105}$

Some of the signs and symptoms of a major depressive episode are identical to those of general medical conditions such as weight loss with untreated diabetes, fatigue with cancer, hypersomnia in early pregnancy, and insomnia in later pregnancy and post partum. ${ }^{106}$ Baile, et.al. comment that major depression is often difficult to diagnose in those with terminal illness, because the apathy and withdrawal associated with depression can be mimicked by cachexia, medications and other factors related to the disease. ${ }^{107}$ Further, they assert that depression may be overdiagnosed in patients with terminal illness. $^{108}$

Ultimately, what we know about depression is that an estimated $7 \%$ of the general population suffers from it, ${ }^{109}$ and distinguishing MDD from depressive disorder due to another medical condition and other forms of depression largely requires eliminating from the picture other potential causes of depression, from medical issues, to life stressors, to medications (including alcohol), to the treatments themselves. In general, primary care practitioners miss the diagnosis in about half of those suffering with some

${ }^{105}$ Ibid., p 182.

106 Ibid., p 164.

${ }^{107}$ Baile, et.al., 1993, p 2787.

108 Ibid.

${ }^{109}$ Diagnostic and Statistical Manual of Mental Disorders, Fifth Edition, 2013, p 165. 
form of depression, ${ }^{110}$ but many of these will improve on their own, as their medical or social situations change, or simply as the depressive disorder runs its course. ${ }^{111}$ Patients with some medical conditions are more prone to depression than others, the reason for which is not fully understood.

While parsing out these differences might be important for diagnostic, and possibly for treatment purposes, they are less relevant with regard to my thesis. That is, whatever the cause of a medical patient's depression, it is the degree of the depression that is key to whether she has capacity. Those with severe depression may be unable to make rational decisions, while those with mild to moderate symptoms, I will show, can demonstrate capacity and have stable preferences over time, even when depression lifts. Before I turn to this literature, however, I wish to describe the relationship between depression and suicide. The data will show that while some medical patients do commit suicide, suicide is no more common in medical patients with depression than in the general population.

\section{Suicide in patients with depression}

The traditional reason to question the capacity of those with depression stems from the perception that depressed patients are more likely to end their lives, and their refusal of treatment is a means of suicide. Predicting exactly who is likely to attempt suicide, however, proves quite difficult. Interestingly, approximately $50 \%$ of people who commit suicide were never diagnosed with a psychiatric disorder. Yet retrospective studies have found that a psychiatric diagnosis of some kind could be established in more than $90 \%$ of such cases, retroactively. This $90 \%$ constitutes a broad category of

${ }^{110}$ Simon and VonKorff, 1995, p 99.
${ }^{111}$ Ibid., p 102. 
diagnoses, not necessarily MDD or other forms of depression. The remaining 50\% commit suicide despite having been in recent contact with a clinician or diagnosed with/treated for a psychiatric disorder. ${ }^{112}$ Further, while patients may regret suicide attempts or view such attempts as a cry for help, it is not clear that the desire for death in those with MDD persists when depression has lifted. Studies of the subsequent mortality rates of suicide survivors show that only about $1-2 \%$ go on to commit suicide within one year, the period in which suicidal risk is greatest. ${ }^{113}$

A consistently described risk factor for suicide is a past history of suicide attempts or threats, but most completed suicides are not preceded by unsuccessful attempts. Those at greatest risk among the general population are males who are single/living alone, with prominent feelings of hopelessness. ${ }^{114}$ Counterintuitively, improvement in depression is associated with an increased risk for suicide. This may reflect a sense of calm once the decision has been made to die, true clinical improvement with a concomitant level of frustration when symptoms recur, or biological changes that truly reflect a calm disposition. ${ }^{115}$ Interestingly, in hospitalized patients who have expressed the wish to refuse lifesaving treatment, when their wishes are ignored and aggressive life support is given, paradoxical suicidal ideation and behavior can develop. ${ }^{116}$

\footnotetext{
112 Goodwin, 2007, 247-8.

113 Siegel, 1982, p 79.

${ }^{114}$ Diagnostic and Statistical Manual of Mental Disorders, Fifth Edition, 2013, p 167.

115 Goodwin, 2007, p 264. This means that a calm demeanor (rather than agitation or psychosis) or even a lifting of depressive symptoms will not help the practitioner to predict when a patient is at increased risk for suicide.

${ }^{116}$ Pauker and Cooper, 1990, p 490.
} 


\section{Suicide in the terminally ill is no more common than in the general}

\section{population}

Studies indicate that while some diseases are associated with increases in depressive illness, medical depressives are less likely to report suicidal feelings. Further, most people with terminal illness do not turn to suicide. Moffic and Paykel conducted a study of medical inpatients, comparing depressed and non-depressed populations. Using the Beck Depression Inventory, comparisons between the two matched samples on 26 symptom ratings showed significant differences on eight symptoms. Depressed patients were less likely to report suicidal feelings, but showed more evidence of feelings of hopelessness and helplessness, anxiety, "a distinct quality to the depression different to normal experience," psychomotor retardation, agitation and self-pity. There were no differences in physiological symptoms such as constipation, anorexia and insomnia, or in indices of somatization, such as anxiety symptoms and hypochondriasis. ${ }^{117}$

It is difficult to know how many people choose to end their lives because they suffer from a chronic or terminal disease, due to a paucity of studies. Karolyn Siegel reports that cancer patients most at risk of suicide are generally at a very advanced stage of disease and are likely to have given indications of poor psychological resources and a limited ability to adjust to illness. ${ }^{118}$ The lay press reported that more than 300 people per year in the United Kingdom with terminal illness took their own lives in $2015 .{ }^{119}$ Given that there were 4513 suicides in the UK, that year, ${ }^{120}$ this indicates that $13.6 \%$ of UK suicides were those with a terminal disease. However, psychological autopsy studies

\footnotetext{
${ }^{117}$ Moffic and Paykel, 1975, p 349.

118 Siegel, 1982, pp 78-9.

${ }_{119}^{11}$ Bingham, 2015.

${ }^{120}$ Ibid.
} 
have found that only $2-3 \%$ of suicide victims suffered from terminal illness at the time of death, suggesting that most people with terminal illness do not foreshorten their lives by suicide. ${ }^{121}$ Quantifying the number of people with terminal illness, in itself, is daunting, since what qualifies as a "terminal illness" may or may not include AIDS, cancer, congestive heart failure, degenerative neurological diseases (such as multiple sclerosis, ascending lateral sclerosis, stroke, Parkinson's disease), trauma, or heart disease, depending on the reporting agency. Siegel notes, "While admittedly little research is available on the relationship of cancer and suicide and the findings are not consistent, there is significant evidence that the incidence of suicide is not higher than in the general population." 122

\section{Decision-making abilities of depressed patients are intact}

As discussed, informed consent requires that an agent have the capacity to make an authentic choice in a manner free of coercion. And as mentioned in Chapter 3, both internal and external pressures can obscure an agent's ability to make authentic choices. Depression is one such pressure. Nevertheless, the presence of mental illness alone does not equal incompetence. Incompetence stems from mental illness "that causes a defect in judgment that would affect the area in question," appreciation. Some authors have expressed concern that affective states may influence competence such that patients may be unable to appreciate the benefits of a treatment, despite retaining the ability to think rationally. ${ }^{124}$

\footnotetext{
${ }^{121}$ Kleepsies, et. al., 2000, p 1167.

122 Siegel, 1982, p 78.

${ }^{123}$ Nichita, 2007, p 55.

${ }^{124}$ Bursztajn, et.al., 1991, p 384.
} 
Admittedly, two important symptoms of depression, those of indecisiveness and apathy, can impair proper decision-making. Nevertheless, many patients retain their ability to reason and make life choices. Richard Sherlock notes of psychiatric patients with severe disease, a patient may be unable to make up his mind regarding therapy, or may change his mind so frequently while in treatment that no therapeutic course can be completed. Apathy may be thought of as a more extreme form of indecisiveness, such that a patient does not care about what is happening to him. While these are volitional, rather than cognitive disabilities, they nonetheless may impede the patient's ability to give informed consent.

The presence of a psychiatric disorder does not necessarily impair capacity, however. Sherlock asserts, "What we will want to know is whether the patient can choose, not that he has made an unwise choice or that his choice has been influenced by factors that are irrelevant from a strictly clinical or rational point of view." ${ }^{125} \mathrm{He}$ suggests that the patient must be able to enter into a process of deliberation about the proposed treatment and sustain that decision over time. ${ }^{126}$ Frequent changes of mind, in the absence of new information coming available to him, raise suspicions that the patient cannot "sustain a consent through time.". 127 Tests, therefore, must concern themselves with more than with the patient's "knowledge" of his situation. Additionally, a patient should be free to act in ways that others might consider unwise, "provided that such a patient fully understands his situation and can freely choose among alternatives presented

\footnotetext{
125 Sherlock, 1984, p 74.

${ }^{126}$ Ibid.

${ }^{127}$ Ibid., p 75.
} 
to him." 128 He also notes that "competency to consent to treatment is, like competency to make out a will or competency to stand trial, neither static nor absolute."129

Studies indicate not only that depression does not necessarily impair a patient's capacity for decision-making, but also that appreciation of one's situation is quite likely to be intact. Psychotic depression is known to interfere with the ability to reason logically in decision-making, and therefore may impair the competence of a patient to consent to treatment. The question of whether patients with MDD without psychotic features are similarly impaired is addressed by Rudnick. ${ }^{130}$ Anhedonia, changes in sleep, appetite and psychomotor activity, loss of energy, cognitive symptoms (poor concentration, feelings of worthlessness, indecisiveness) and pessimism regarding the self, the world and the future characterize depression. However, these symptoms may not impair competence according to the standard notion, as they do not necessarily disrupt abilities to express oneself, to understand, to reason and to appreciate one's situation, so long as they are not accompanied by psychotic features (such as delusions of guilt or nihilism). ${ }^{131}$ Our concern, then, is with both reasoning ability and with symptoms of anhedonia. Research demonstrates that neither age nor depressive illness necessarily impair capacity for decision-making.

A study by Stanley, et.al. compared three groups of elderly patients, totaling 103 individuals, enrolled in a drug treatment trial. Patients with dementia, patients with MDD and a control group were evaluated with the Guild Memory test and the Hamilton Depression scale. They found the cognitively impaired group, as expected, to

\footnotetext{
128 Ibid.

${ }^{129}$ Ibid., p 76.

${ }^{130}$ Rudnick, 2002.

131 Ibid., p 152.
} 
demonstrate poorer overall comprehension of consent information. The depressed elderly, however, obtained scores similar to those of the control group. The purpose of the treatment was the only element in which the depressed elderly had scores lower than the control group $(\mathrm{p}<.08)$. The authors thought this might be related to a denial of illness in the depressed group and, therefore, a lack of understanding about why they should be treated. The authors concluded that depression in the elderly, in and of itself, "does not pose a particular problem in understanding consent information." 132 What would be important to evaluate, then, would be if denial (that is, poor insight or appreciation) poses an impediment to capacity.

One study that evaluated both comprehension and appreciation was the validation study of the MacCAT-T assessment tool, of 1995. This study evaluated 75 patients with schizophrenia, 92 with MDD and 82 with angina, and compared them with three demographically matched groups who had never been hospitalized for treatment of mental disorders or for cardiac conditions. Psychiatric screening was conducted, with severity of illness calculated using the Brief Psychiatric Rating Scale (BPRS) and the Beck Depression Inventory (BDI). Verbal cognitive functioning was evaluated with three subtests of the Wechsler Adult Intelligence Scale-Revised (WAIS-R). ${ }^{133}$ The authors found that nearly $50 \%$ of the schizophrenia group and $76 \%$ of the depression group performed in the "adequate" range across all decision-making measures, and a "significant proportion" performed at or above the mean for persons without mental illness. Using the "understanding standard" for legal competence, the rate of adequate performance rose to roughly $75 \%$ for patients with schizophrenia and to approximately

${ }^{132}$ Stanley, et. al., 1988, p 57.

${ }^{133}$ Grisso and Appelbaum, 1995, pp 153-4. 
$90 \%$ or more for patients with depression. For any given measure, $25 \%$ of the schizophrenic group scored in the "impaired" range, compared with 5-7\% of angina patients and $2 \%$ of community controls. ${ }^{134}$

A subsequent study of 26 non-hospitalized female patients with MDD of moderate intensity found the mean score on the understanding scale to be 23.33 (scale of $0-26$ ), with no subjects scoring below 20 . The mean score on the appreciation scale was 4.89 (scale of 0-6) and the mean score on the reasoning scale was 6.50 (scale $0-8$ ). ${ }^{135}$ The extent of depressive symptoms did not seem to affect the level of performance. ${ }^{136}$

\section{Depression and coherence of end-of-life preferences}

MDD is characterized by the predominance of sadness and disinterest, which itself may diminish preferences in general, especially preferences for productive activities such as work, recreation, or even life itself. ${ }^{137}$ Rudnick assesses how the coherence of preferences might contribute to the assessment of competence, in addition to the standard notions of competence. While preferences from the remote past may not be helpful, Rudnick suggests comparing the preferences of the individual during depression to those held when not depressed, particularly preferences regarding death and medical treatment. ${ }^{138}$ If past treatment preferences have been established, the practitioner should determine whether they are consistent with her current treatment consent or refusal. If past treatment preferences cannot be established, a therapeutic trial to treat depression

\footnotetext{
${ }^{134}$ Ibid., p 171.

135 Appelbaum, et.al., 1999, p 1382.

136 Ibid., p 1383.

${ }^{137}$ Rudnick, 2002, p153.

${ }^{138}$ Ibid.
} 
can be attempted. If successful, the patient's competent treatment preferences can be established at that time. ${ }^{139}$

\section{End-of-life preferences do not differ between depressed and non-depressed}

\section{patients}

Correlating past and present preferences can be quite helpful. But in situations in which prior preferences are unknown, in light of dramatic changes of events, or when treatment decisions cannot be delayed for months while waiting for depression to improve, practitioners need other guidance. Studies of patients with medical illness, with and without depression, at varying ages, have explored the durability and types of end-oflife choices that patients make. Such studies help to establish the likelihood that a patient's expressed choices are authentic, and may assist the practitioner who is assessing these challenging cases.

As noted previously, Stanley, et.al. found that comprehension in depressed elderly patients did not differ significantly from the control group of younger patients, indicating that depression in the elderly, in and of itself, does not appear to pose a problem in understanding consent information. ${ }^{140}$ This is in agreement with another study by Peselow, et.al., who found that the seriously depressed non-elderly population did not differ in their capacity to give informed consent when compared to an age-matched group of non-depressed individuals. ${ }^{141}$

Lee and Ganzini found that depressed elderly patients, when provided with a hypothetical scenario of illness, preferred fewer life-sustaining interventions than a

139 Ibid.

140 Stanley, et.al. 1988, p 57.

${ }^{141}$ Peselow, et.al., 1982. 
similar group of non-depressed patients in some situations. They did not differ from controls in the number and types of therapies they desired, when the overall prognosis was poor. However, they refused more procedures than the controls in their current health and in situations with a good prognosis. ${ }^{142}$ Other studies, however, such as that of Cohen-Mansfield, et.al., have found no relationship between the level of depression as measured by the Geriatric Depression Scale (GDS) and the tendency of nursing home patients either to accept or refuse life-sustaining interventions. ${ }^{143}$ Michelson, et.al., found no correlation between GDS scores and choices made by subjects in response to hypothetical scenarios. ${ }^{144}$ A survey by Uhlmann and Pearlman found that depression did not affect patients' preferences for mechanical ventilation, ${ }^{145}$ and Danis, et.al., found a desire for cardiopulmonary resuscitation (CPR) in $37 \%$ of nursing home residents in the event of a critical illness and $16 \%$ in the event of a terminal illness. ${ }^{146}$ The preponderance of the evidence, therefore, shows little correlation between the severity of depression and end-of-life preferences.

\section{End-of-life preferences endure}

In 1994, Lee and Ganzini examined whether elderly patients, after treatment for depression, would demonstrate an increased desire for life-sustaining medical therapy. ${ }^{147}$ Demographically matched cohorts of medical patients from the Veteran's Affairs Medical Center of Portland, Oregon, over the age of 65, 50 of whom were depressed and 50 who were not, were analyzed. Four to six months after the initial evaluation, the

\footnotetext{
${ }^{142}$ Lee and Ganzini, 1992, p 987.

${ }^{143}$ Cohen-Mansfield, et.al., 1991, p 289.

${ }^{144}$ Michelson, et.al. 1991, p 358.

${ }^{145}$ Uhlmann and Pearlman, 1991, p 495.

${ }^{146}$ Danis, et.al., 1991, pp 883-4.

${ }^{147}$ Lee and Ganzini, 1994.
} 
patients were reevaluated. When comparing both groups, there were no changes in scenario scores and a high degree of agreement between the initial and final responses. When control patients changed their minds, it was in favor of more treatment in the two "good prognosis" scenarios (pneumonia and renal failure) and in the direction of less treatment in the "poor prognosis" scenario (stroke). ${ }^{148}$ Thirty-eight percent of the originally depressed patients were no longer depressed at follow-up, but $4 \%$ of the control group had become depressed. Of the depressed subjects who recovered, $53 \%$ had received pharmacologic treatment and 2 had been hospitalized in a psychiatric in-patient facility. Suicidal ideation was rare. Depressed subjects whose depression remitted were as likely to change from refusing to desiring a treatment as vice-versa. But those who remained depressed were likely to refuse an intervention they had initially desired. ${ }^{149}$

The most consistently stable choices for all scenarios in all groups were with regard to CPR. The authors assert that the stability of CPR preferences in all groups depressed or not, indicates that medically ill, mildly to moderately depressed patients without cognitive impairment can make authentic choices about their code status, which endure once their depression is treated. ${ }^{150}$ Similar stability of CPR preferences over the course of 6 months to 2 years was found by researchers examining cohorts of HIVinfected patients, oncology patients and healthy members of the public. ${ }^{151}$ The authors also found stability of preferences with second and third interview, such that repeated asking appears to reinforce preferences.

\footnotetext{
${ }^{148}$ Ibid., pp M17-M18.

${ }^{149}$ Ibid., pp M18-M19.

${ }^{150}$ Ibid., pp M19-M20.

${ }^{151}$ Emanuel, et.al., 1994, p 209.
} 
Another study published that year by Ganzini, et.al. evaluated the desire for lifesustaining medical therapy in 43 patients over age 60, suffering from MDD. Twenty-four subjects $(56 \%)$ were discharged with remission in their depression. However, the number of interventions desired (intravenous fluids, blood transfusion, nasogastric feeding tube, intensive care, mechanical ventilatory support and CPR) did not differ from the number desired after treatment of depression. Despite successful treatment of depression, 67$88 \%$ of subjects did not change their response to any treatment questions. The authors note that in $74 \%$ of patients with MDD, remission of depression did not result in an increase in preferences for life-sustaining interventions. Those who did change their preferences in favor of increased intervention were "significantly more depressed than those who were stable in their preferences." ${ }^{\prime 152}$ However, treatment of depressed elderly patients "initially without hope" did not appear to increase their interest in life-sustaining medical treatment. ${ }^{153}$ The stability of preferences in patients with depression should reassure practitioners that in the majority of cases, the wishes expressed by them endures, even with remission of depressive symptoms. Further, changes in preferences were seen only in the more severely depressed. This also reinforces the notion that mild to moderate depression does not significantly alter end-of-life choices.

Lee and Ganzini conclude that their studies add to the growing body of evidence that depression does not necessarily influence patients to refuse life-sustaining therapy and that treatment of mild to moderate depression does not consistently result in acceptance of previously shunned interventions. ${ }^{154}$ Ganzini, et.al. further point out that

${ }^{152}$ Ganzini, et.al., 1994, p 1634.

153 Ganzini, quoted by Sullivan and Youngner, 1994, p 974.

${ }^{154}$ Lee and Ganzini, 1994, p M20. 
"effective depression treatment did not alter the kinds of decision that these subjects

made." ${ }^{155}$ So, it appears that patients with depression tend to eschew life-extending treatments, and their end-of-life preferences do not change, even when their depression has lifted.

The endurance of choice demonstrates authenticity of the preferences expressed by depressed patients. Authenticity is a concern even under the best of circumstances, but these studies show that we can trust the choices made by depressed patients, as much as anybody else. While it would be even more convincing to compare a patient's preferences before becoming depressed to her preferences during a depressed state, there is little, if any research addressing this question. Every attempt should be made to ascertain the patient's wishes before the onset of a depressive episode, but such information may not be available. The question of whether a bout of depression might affect a patient's self-conception, altering her preferences indefinitely, is beyond the scope of this work. But practitioners can be reassured by the data demonstrating continuity of end-of-life choices. That said, I do not believe that those with severe depression fit into the same category as those with mild to moderate depression. Those with psychotic episodes or severe depression are likely to fail capacity exams, making authenticity issues less likely to arise. Nevertheless, practitioners have good grounds to question the authenticity of the choices in these patients. I assert that based upon these studies, mildly to moderately depressed patients can refuse treatment and make end-oflife decisions. Such patients make reliable, enduring choices about their medical wishes. And while it is ideal to establish past treatment preferences and/or initiate a therapeutic

${ }^{155}$ Ganzini, et.al.1994, p 1635. 
trial to treat a patient's depression, as Rudnick suggests, it is not necessary; a mild to moderately depressed patient's expressed preferences regarding end-of-life care are reliable and authentic.

\section{Exceptional cases}

In Chapters 1 and 2 I identified problems with the informed consent process, as it is employed currently. The Defeater Problem and the Authenticity vs. Agency Question pertain directly to the exceptional cases I am addressing. Recall, with the Defeater Problem, the practitioner "jumps to conclusions," thinking the patient lacks capacity for informed consent, when in fact she is competent. With the Authenticity vs. Agency Question, practitioners utilize whichever conception of autonomy suits the situation, in their mind. Practitioners appeal to agency for decisional competence to refuse treatment, but when the patient's refusal of treatment seems inconsistent with who the patient is, they appeal to authenticity. While this may be appropriate at times, they risk dismissing an agent's competence prematurely, without a thorough examination of the patient's values and capacity for decision-making.

Without question, cases in which a patient manifests symptoms of depression should give the practitioner pause. In Chapter 2, I discussed some red flags such as change of mind or evidence of peer pressure, and in this chapter I have pointed out symptoms, such as anhedonia, as well as signs, such as weight loss, that may accompany

depression. A depressed patient may be even more likely to succumb to peer pressure or to refuse treatment. Grisso and Appelbaum also point out that patients may be more inclined to consent to treatments that are more invasive or risky, when experiencing depression. Anxiety and dementia may be confused with depression, or may serve to 
exacerbate the condition. ${ }^{156}$ Even so, the symptoms that satisfy the criteria for clinical depression in the Diagnostic and Statistical Manual of Mental Disorders ${ }^{157}$ are not necessarily the same symptoms that impair the ability to make lifesaving treatment decisions. ${ }^{158}$ Furthermore, studies have shown that patients with mild to moderate depression demonstrate consistent choices pertaining to end-of-life issues, even when their depression has lifted.

Once concern about depression prompts questions of competence for decisionmaking, the next step is to assess capacity. As I have explained, Substantial Autonomy should be the standard to which we hold agents making decisions about medical treatment and refusal. Further, evidence required for Threshold Competence will vary, depending on the question at hand. Key is establishing the criteria a patient must meet to have Threshold Competence for decision-making.

\section{Screening tools of capacity for decisional competence}

As discussed in Chapter 1, a number of approaches to competence have been employed, from an agent's ability merely to express a choice to the ability to manipulate information and apply it to her situation. ${ }^{159}$ It should be noted that since autonomy focuses on the process of decision-making rather than the outcome, an autonomous choice is one that is the product of autonomous action, regardless of whether its result is "good for" or "bad for" the agent. Therefore, competency determinations should address the capacity of the decision maker, rather than the reasonableness of the choice; it is the

\footnotetext{
${ }^{156}$ Grisso and Appelbaum, 1998, pp 62-75.

${ }^{157}$ Diagnostic and Statistical Manual of Mental Disorders, Fifth Edition, 2013.

158 Burnell, 1995, p 511.

${ }^{159}$ Kutner, et.al., 1991, p 1405.
} 
decision-making process that is key. ${ }^{160}$ However, the "reasonable outcome of choice" test of competency, which focuses on the outcome (reaching the "right" or "responsible" decision) is used "more often than might be admitted by both physicians and courts," according to Roth, Meisel and Lidz. ${ }^{161}$ Laws for involuntary treatment are premised on the idea that the patient needs treatment, but the patient has not obtained treatment on her own initiative, therefore her decision is incorrect, which means she is incompetent, justifying the involuntary imposition of treatment. ${ }^{162}$

A number of testing instruments for capacity have been developed. These include Understanding Treatment Disclosures (UTD), Perceptions of Disorder (POD), Thinking Rationally About Treatment (TRAT), the Mini Mental Status Exam (MMSE), ${ }^{163}$ the Hopkins Competency Assessment Test (HCAT), ${ }^{164}$ the MacArthur Treatment Competence Research Instrument (MacCAT-T), ${ }^{165}$ the Aid to Capacity Evaluation (ACE), ${ }^{166}$ the Assessment of Older Adults with Diminished Capacity, ${ }^{167}$ the Structured Interview for Competency Incompetency Assessment Testing and Ranking Inventory (SICIATRI), the Competency Questionnaire (CQ), the Measure of Competency to Render Informed Treatment Decision (MOC), Measuring Understanding of Disclosure (MUD) and the Disclosure Consent Check List (DCCL). ${ }^{168}$

${ }^{160}$ Berg, et.al., 1995-6, p 352, fn 22.

161 Roth, Meisel and Lidz, 1977, pp 280-1.

162 Ibid., p 281.

${ }^{163}$ Folstein, 1975.

164 Janofsky, 1992.

165 Grisso, 1997.

166 Etchells.

${ }^{167}$ Assessment of Older Adults with Diminished Capacity.

${ }^{168}$ Welie, 2001, p 140. 
Roth, Meisel and Lidz assert that a useful test for competency is one that (1) can be reliably applied, (2) is mutually acceptable or at least comprehensible to physicians, lawyers and judges, and (3) is set at a level capable of striking an acceptable balance between preserving individual autonomy and providing needed medical care. They note that reliability is improved when competency tests rely on "objectively ascertainable patient behavior rather than on inferred and probably unknowable mental status." ${ }^{169}$

I must comment on their third criterion, because what constitutes "needed medical care," that is, medical good, may not be the treatment the patient desires. Recall Dworkin's approach to understanding the good of persons, discussed in Chapter 1, which values respect as an independent agent with a right to make decisions for oneself, over longer life or greater health. ${ }^{170}$ If practitioners place too high a value upon physiological/medical good, they could intentionally or inadvertently set the bar for competency at a level that the patient cannot attain. This is the nature of the Defeater Problem, where providers override the wishes of the patient, due to circumstances such as pain or depression, thinking the patient "fails the test" for informed consent, but in fact the patient has capacity. The informed consent coding that I propose is designed to avoid such arbitrariness in the assessment of capacity. As mentioned before, pain and depression are red flags, demanding greater attention to capacity issues. But practitioners should not doubt the patient's capacity, out of hand, in light of these concerns. Careful assessment of capacity and patient preferences is required, bearing in mind that medical good may not be in the patient's best interests, as she views them.

${ }^{169}$ Roth, Meisel and Lidz, 1977, p 280.

${ }^{170}$ Dworkin, 2010, p 7. 
A weakness of all tests in the assessment of patient competence is that even the "objective" tests are subject to influence by the assessor. The assessor should "know what she is doing." Those unfamiliar with the construction of the tests can misadminister them. ${ }^{171}$ Wilie also points out two other issues: the requirement of a "supportive situation" and the role of emotions in the competency assessment. A low score on a test may be the result of the interaction between examiner and examinee. Situational circumstances, including poor instruction of the examinee, can skew the score. What counts as a "supportive situation" may vary, and circumstances may not be ideal to provide the optimal testing environment (including mix of personalities, empathy and communication skills). In addition, the examiner must be careful not to "help" the patient and substitute her own decision-making, by simplifying information for the patient to the point of omitting important aspects of treatment. ${ }^{172}$

Appelbaum and Roth echo many of Wile's sentiments and recommend considering:

1. Psychodynamic elements of the patient's personality

2. The accuracy of the historical information conveyed by the patient

3. The accuracy and completeness of the information disclosed to the patient

4. The stability of the patient's mental status over time

5. The effect of the setting in which consent is obtained ${ }^{173}$

Of note, these authors mention that the relationship between the patient and the practitioner can provoke anxiety in the patient. In some, the consent process can provoke anxiety sufficient for the patient to refuse the procedure. The practitioner should attempt to verify the accuracy of the information the patient provides, when there is question of

${ }^{171}$ Wilie, 2001, p 145.

172 Ibid, p 146.

${ }^{173}$ Appelbaum and Roth, 1981, p 1462. 
the veracity of her statements. Further, the information that has been provided to the patient about the proposed treatment should be evaluated. Preferably, the treating physician should explain or re-explain the treatment in the presence of the clinician performing the competence evaluation. In non-emergent situations, more than one evaluation of patient competence should be conducted, as competency can fluctuate from illness and psychodynamic factors. Appelbaum and Roth recommend two contacts with the patient on at least two different days. Finally, certain settings may provoke anxiety, so minimizing such situations is recommended. ${ }^{174}$

\section{Applying Threshold Competence to the depressed patient}

Once the practitioner has diagnosed depression and decided upon the capacity instrument to use, determining if the patient "passes the test" for capacity largely depends upon the treatment question at hand. Of course, a patient who is unable to participate in the evaluation for capacity does not meet Threshold Competence. She may have the capacity to choose ibuprofen (Motrin) over hydrocodone with acetaminophen (Norco, an opioid pain medication), but certainly cannot ask for PAS, for example. Again, a patient lacking the attention to participate in the capacity evaluation will not "pass the test." Practitioners are concerned that patients with affective disorders can understand the potential harms and benefits of a treatment, yet fail to appreciate its benefits. ${ }^{175}$

Even without the system of informed consent coding I have proposed, some situations clearly require a high level of comprehension of the facts of the matter, as well as of implications for refusal of treatment. Substantial Autonomy for such situations

\footnotetext{
${ }^{174}$ Ibid., pp 1463-5.

${ }^{175}$ Sullivan and Youngner, 1994, p 975.
} 
should be high, and Threshold Competence will similarly require a good deal of evidence of decision-making ability.

The degree to which intellectual and social functioning are impaired relates directly to the question of an agent's capacity for decision-making. Patients who do not manifest severe depression likely have capacity, but a formal capacity exam will assist in assuring competence. Next we should consider the types of decisions a patient is asked to make. Typically, when a patient chooses a treatment plan recommended by her physician, her competence goes unquestioned. Recall, this can lead to the Expedience Problem, where deep exploration of the patient's capacity is not pursued. A patient could be acquiescing to the desires of family or friends (peer pressure) rather than choosing based upon her real self values. It is important that the practitioner explore what motivates a patient's choices, to assure that peer pressure or other elements are not exerting undue influence.

More likely, however, practitioners would be concerned about a refusal of treatment. The choice of palliative care is receiving greater attention and with it, societal approval. Were a patient to express a preference for less aggressive treatment, focusing on wellbeing and comfort, she might meet less resistance than were she to request PAS. Whichever capacity exam is utilized, it should address the type of decision she is making; choosing palliative care over aggressive chemotherapy requires different Threshold Competence than requesting PAS over other options. The informed consent coding system I propose would categorize a request for PAS very high on a zero-to-ten scale, meaning that the highest level of evidence would be required to establish a patient's competence. Palliative care, depending on the situation, would have a lower numeric 
ranking. A coding number of 10 would entail demonstrating comprehension of the matters at hand, as well as insight regarding how treatment or its refusal will affect her condition. Arguably, the patient should be asked to consider the impact her decision may make on her loved ones, as well, to show the deepest level of insight possible.

Even without informed consent coding, evaluation of comprehension and insight is feasible. The capacity exam also must look for the red flags I discuss in Chapter 2, such as change in mental state, refusal of treatment, consenting to invasive or risky treatment, change of mind and signs of peer pressure. Also, assuring that the capacity exam is conducted under circumstances that are less likely to provoke anxiety is important.

Mild to moderately depressed patients are likely to do well on assessments of understanding of their diagnosis and the proposed treatment, as well as with expressing the likely consequences of refusing it. If a patient expresses a change of heart regarding treatment, such as choosing a less aggressive treatment, when before she wished for "everything to be done," the reason for the change in attitude must be accounted for. It is possible that, having experienced chemotherapy before, for example, a patient may simply not be interested in contending with its side effects, even if her life might be extended. Her change of mind might reflect new knowledge that she did not possess a few years before. It is also possible that with a month or so of antidepressant medication, she might change her attitude about pursuing more aggressive management of her cancer, although the research I have presented has not borne this out. 
In situations where patients have been found to be severely depressed, a trial course of antidepressant medication has been recommended. ${ }^{176}$ At times, this means that a patient has her life sustained via mechanical means, while clinicians "wait and see" if her mood improves or if her condition either improves or worsens, effectively tipping the scales in the direction of continued life-sustaining treatment over withdrawal of care. Such cases are those about which I have great concern, since patients may endure end-oflife treatments that they have requested to forgo. Further, many such patients have anticipated such an end and requested PAS, only to become too ill to self-administer the medication to end their lives, in compliance with laws in those states where PAS is legal. ${ }^{177}$ Unfortunately for the severely depressed, they simply may not be able to meet criteria for competence. However, I reassert that even patients with mild to moderate depression refusing suggested care or requesting PAS can and should be afforded the opportunity to demonstrate Threshold Competence for decision-making.

\section{The role of the practitioner}

Both advocates of PAS (and other end-of-life choices) and their opponents express concern over how the practitioner's own biases may influence her assessment of the patient. The tradition of placing the burden of proof regarding competence upon the patient, simply because she is refusing care, undermines patient autonomy. Additionally, a practitioner's bias against any course of action that runs counter to her recommendations poses a potential threat to a patient's choice to terminate treatment or end her life.

\footnotetext{
${ }^{176}$ Rudnick, 2002, p 153.

${ }^{177}$ Where PAS is legal in the US, patients must be capable of self-administering the lethal medications. Family members or medical professionals, by law are prevented from giving them.
} 
Opponents of PAS note a different problem, asserting that those making the clinical evaluation for capacity may see depression as a "reasonable" response to serious medical illness, prompting evaluators to encourage PAS as an option. ${ }^{178}$ This "pseudoempathy" may lead practitioners to underestimate the quality of life seriously ill patients may enjoy. ${ }^{179}$ Such practitioners believe that "there is something about the despair of persons with disabilities and incurable illnesses who request assistance in dying that is qualitatively different from suicidal despair in other persons and, therefore, depression related to incurable health conditions calls for less rigorous suicide prevention efforts than depression in otherwise healthy individuals." ${ }^{, 180}$

I wish to be clear that this is not the position I hold. The above argument cites "rational depression," as a type of despair engendered by an unremitting illness or disability. Said depression is considered a reasonable, normal and intractable response to disability, with assisted death being a dignified solution. ${ }^{181}$ While this may or may not be true, it is not the basis upon which I argue that depressed patients can make authentic choices about their care. Rather, I argue that mild to moderate depression does not significantly alter the preferences of patients, so their expressed wishes should be taken as reliable and authentic.

Carol J. Gill advocates for the disabled, arguing against PAS on the grounds that social problems (lack of affordable care for the disabled, inability to find care outside of nursing homes and institutions, isolation and lack of meaningful social roles) drive the disabled to request PAS. She denounces "society's willingness to facilitate dying in

${ }^{178}$ Sullivan and Youngner, 1994, p 971.

179 Ibid., p 976.

${ }^{180}$ Gill, 2004, p 178.

${ }^{181}$ Ibid., pp 178-9. 
persons with disabilities and other irreversible conditions rather than offering suicide intervention or addressing the remediable social problems underling the death wish." "182 Health care professionals are complicit, she argues, in that they underestimate the potential and quality of life of people with disabilities and are ill-informed about services available to the disabled. Because they are viewed as authority figures, their ignorance results in patients following their endorsement of assisted death as being appropriate, rather than receiving intervention. ${ }^{183}$

For these reasons, it is important for practitioners to maintain objectivity in their assessments of patients. And despite these challenges and potential pitfalls, the practitioner's role in diagnosing depression and assessing its affects on capacity cannot be avoided. I believe that with careful assessment of the exceptional cases, objective assessments that evaluate competence as well as a patient's system of values can be completed in a manner that preserves the wishes of the patient, even when life-extending treatments are rejected by the patient. Utilizing Rigorous Informed Consent can ensure that patients with depression have Sufficient Autonomy for medical decision-making.

182 Ibid., p 172.

${ }^{183}$ Ibid., p 184. 


\section{CHAPTER 5: CONCLUSIONS}

My project began with an exploration of problems with the informed consent process, many of which result from complacency on the part of practitioners, coupled with a tendency for all of us to sign documents and "accept terms" without much thought. Our goal of respecting autonomy, through the use of informed consent, fails when practitioners neglect their duty to employ Rigorous Informed Consent. This results in situations that undermine patient autonomy, through a failure to ensure that all three components of informed consent be present: that the agent have capacity for decisionmaking, that the agent be informed, and that the agent's decision be voluntary--or as I have suggested, authentic.

Such failures are noted in the Expedience Problem, where the patient has capacity, but it is not adequately assessed, or with the Least Agreement Problem, where the physician chooses the least-rigorous standard possible, to ensure agreement from her patient. Paternalism can be introduced in the Defeater Problem, where the practitioner jumps to the conclusion that the patient lacks capacity, or with the False Consent Problem, where the patient's capacity and/or authenticity are lacking, yet go unexamined.

I have suggested that greater attention to the elements of informed consent, utilizing informed consent specialists and a system of informed consent coding, for example, can help ensure that patients possess Threshold Competence for a given treatment decision. Admittedly, informed consent specialists pose the potential for adding costs to medical procedures, but we must ask ourselves what measures we would wish to take to ensure respect for autonomy.

Certainly, implementing the system of informed consent coding that I suggest 
would be a gargantuan task. But one should remember that coding systems such as the ICD-10 enjoy worldwide acceptance - and they were not developed overnight. A system of disease classification was first embarked upon in 1785, with the adoption of the International List of Causes of death at the meeting of the International Statistical Institute in $1891 .^{184}$ Over the course of the last century, numerous statistical classification systems have been discussed, and the ICD system was in its sixth revision by $1946 .{ }^{185}$ In fact, while other iterations of the ICD were in place, the tenth version was in the planning stages starting in 1983, was not completed until 1992, and was not implemented until October, 2016. ${ }^{186}$ Clearly a great deal of time and effort has been expended in the interest of medical coding.

I would anticipate that development of the system I describe would require similar large-scale interest and funding, such as from the National Institute of Medicine or the World Health Organization. Beginning with a surgical subspecialty would be the most feasible manner in which to proceed, since surgeries are well-described, focused and limited in duration. Developing a coding system for ophthalmology, for example, would be very limited in scope, and a good starting place. Experts in the field would be called upon to develop and delineate a numeric assignment to procedures, from cataract surgery to laser treatment of diabetic retinopathy, based upon risk assessment and other factors. Informed consent is meant to operationalize respect for autonomy. But some argue that the process of obtaining informed consent is itself paternalistic because it is designed to ferret out cases where patients lack competence. I must concede that one can

${ }^{184}$ World Health Organization.

185 Ibid.

${ }^{186}$ WebPT. 
adopt this perspective, but I think the intent of the informed consent process is to protect patients from practitioners' overstepping their bounds and infringing upon patients' rights. Without the informed consent process, patients are even more likely to see their autonomy infringed.

Whether a threshold for autonomy should be fixed across cases or vary by the situation is another issue of contention for some, although the idea of a sliding scale of competence enjoys widespread acceptance. ${ }^{187}$ I believe that a single threshold across cases threatens to be even more paternalistic, by limiting the autonomy of normal choosers if the bar is set too high. Setting the bar too low could make poor decisionmaking commonplace, and this also is unacceptable. That an agent at a single instant might be competent for some medical decisions and not others emphasizes the need for variable thresholds for competence

As I have noted, simply saying, "We must do a better job" at respecting autonomy is insufficient, so I have recommended not only that we demand that clinicians practice Rigorous Informed Consent, but that we consider an approach to informed consent that recognizes the limitations of real-world agents. No one can be perfectly autonomous, so competence requires Substantial Autonomy for decision-making. Threshold Competence varies with the circumstances surrounding the diagnosis and treatment plan for that situation. I have emphasized the importance of authenticity in this assessment. Admittedly, epistemic difficulties limit our ability to know whether an agent's desires reflect her real self views, but authenticity is too important a matter to ignore. For this

${ }^{187}$ Beauchamp and Childress, 2009, pp 113-4, Feinberg, 1986, p 30, Dworkin, 1988, pp 31-2, and Buchanan and Brock, 1989, p 53. 
reason, I have taken care to describe domains of influence upon authenticity, as well as red flags that may indicate inauthentic choice and alert practitioners to these matters.

Deliberate navigation of the informed consent process involves not only assessing for authenticity, proper delivery of information, and comprehension of the diagnosis and treatment options, but also careful assessment of the exceptional cases, in which a patient's competence so frequently is called into question. Assessment of an exceptional case such as depression requires acknowledgement by practitioners that patients who possess Threshold Competence should be allowed to choose treatments with which the practitioner might disagree. Indeed, red flags such as a change of mind or affect deserve great scrutiny, and end-of-life choices often merit the highest Threshold Competence standards.

A paucity of studies of patients with the combination of depression, chronic and/or terminal disease, end-of-life preferences or suicidal behavior limits the certainty with which I can draw conclusions about the exceptional cases. My work is but a jumping-off point for such matters. I fear that patients with depression at the end of life are too easily dismissed as lacking competence. Even worse, some of the most introspective and self-aware patients are those who are requesting PAS or other end-oflife measures, and nonetheless are subjected to paternalistic treatment on the part of their clinicians. Careful attention to patients making end-of-life requests can be better achieved through the measures I have recommended. Despite epistemic limitations, I argue that practitioners doing their due diligence will find that patients suffering from mild to moderate depression can demonstrate Substantial Autonomy and possess 
Threshold Competence for making informed, authentic requests in accordance with their real self values. 


\section{REFERENCES}

Appelbaum, Paul S. and Roth, Loren H., "Clinical Issues in the Assessment of Competency," Am J Psychiatry, Vol 138, No 11, November 1981, pp 1462-7.

Appelbaum, Paul S., Grisso, Thomas, Frank, Ellen, et.al., "Competence of Depressed Patients for Consent to Research," Am J Psychiatry, Vol 156, No 9, September 1999, pp 1380-4.

Assessment of Older Adults with Diminished Capacity: A Handbook for Psychologists (C) American Bar Association Commission on Law and Aging - American Psychological Association.

Baile, Walter F., DiMaggio, Joseph R., Schapiria, David V., et.al., “The Request for Assistance in Dying: The Need for Psychiatric Consultation," Cancer, Vol 72, 1993, pp 2788-91.

Beauchamp, Tom L. and Childress, James F., Principles of Biomedical Ethics, Sixth Edition, Oxford University Press, New York, 2009.

Berg, Jessica Wilen, Appelbaurm, Paul S. and Grisso, Thomas, "Constructing Competence: Formulating Standards of Legal Competence to Make Medical Decisions," 48 Rutgers Law Review, 1995-6, pp 345-396.

Bingham, John, “Assisted Dying: More than 300 Terminally Ill People a Year Committing Suicide, The Telegraph, October 15, 2015.

http://www.telegraph.co.uk/news/uknews/assisted-dying/11163992/Assisted-dying-morethan-300-terminally-ill-people-a-year-committing-suicide.html, accessed 02/18/17.

Blackhall, L.J., et. al., "Ethnicity and Attitudes Toward Patient Autonomy," JAMA, 274, 1995, pp 820-5.

Bruckner, DW, “Colburn on Covert Influences,” Utilitas, Vol 23, 2011, pp 451-457.

Brudney, Daniel and Lantos, John, "Agency and Authenticity: Which Value Grounds Patient Choice?" Theoretical Medical Bioethics, 32, 2011, pp 217-227.

Buchanan, Allen E. and Brock, Dan W., Deciding for Others: The Ethics of Surrogate Decision-making, Cambridge University Press, New York, 1989.

Burnell, George M., "Psychiatric Assessment of the Suicidal Terminally Ill," Hawaii Medical Journal, Vol 54, April 1995, pp 510-3.

Bursztajn, Harold J., Harding, Herndon P., Gutheil, Thomas G., et.al., "Beyond Cognition: The Role of Disordered Affective States in Impairing Competence to Consent to Treatment," Bull Am Acad Psychiatry Law, Vol 19, No 4, 1001, pp 383-8. 
Christman, J, The Politics of Persons: Individual Autonomy and

Socio-historical Selves, Cambridge University Press, Cambridge, 2009.

Cohen-Mansfield, J., Rabinovich, BA, Lipson, S., et.al., "The Decision to Execute a Durable Power of Attorney for Health Care and Preferences Regarding the Utilization of Life-Sustaining Treatments in Nursing Home Residents," Arch Intern Med, Vol 151, 1991, pp 289-94.

Consent to Surgical or Other Medical Procedure, Mercy Health, SVMMC Form 01006 Rev 9/14.

Danis, M, Southerland, L.I, Garrett, J.M., et.al. "A Prospective Study of Advance Directives for Life-Sustaining Care," N Engl J Med, Vol 324, 1991, pp 882-8.

DeGrazia, D, Human Identity and Bioethics. Cambridge University Press, Cambridge, 2005.

Diagnostic and Statistical Manual of Mental Disorders, Fifth Edition, American Psychiatric Association, Washington DC, 2013.

Dworkin, Gerald, The Theory and Practice of Autonomy, Cambridge University Press, New York, 1988.

Dworkin, Gerald, "Paternalism," Stanford Encyclopedia of Philosophy, revised June 1, 2010, pp 1-9.

Emanuel, Linda L., Emanuel, Ezekiel J., Stoeckle, John D., et.al., “Advance Directives: Stability of Patients' Treatment Choices," Arch Intern Med, Vol 154, Jan 24, 1994, pp 209-17.

Etchells, Edward, Joint Centre for Bioethics - Aid To Capacity Evaluation (ACE) http://www.utoronto.ca/jcb/disclaimers/ace.htm

Feinberg, Joel, Harm to Self: The Moral Limits of the Criminal Law, Oxford University Press, New York, 1986.

Frankfurt, Harry G., "Freedom of the Will and the Concept of a Person," The Journal of Philosophy, Vol. 68, No. 1, January 14, 1971, pp 5-20.

Frankfurt, Harry, "Identification and Wholeheartedness," Responsibility, Character, and the Emotions: New Essays in Moral Psychology, Schoeman, Ferdinand, Ed., Cambridge University Press, New York, 1987. 
Folstein, MF, Folstein, SE, McHugh, PR, "Mini-Mental State: A Practical Method for Grading the Cognitive State of Patients for the Clinician," J Psychiat Res, Vol 12, 1975, pp 189-198.

Ganzini, Linda, Lee, Melinda A, Heintz, Ronald, et.al., "The Effect of Depression Treatment on Elderly Patients' Preferences for Life-Sustaining Medical Therapy," Am J Psychiatry, Vol 15, No 11, November 1994, pp 1631-6.

Gill, Carol J., "Depression in the Context of Disability and the 'Right to Die,"' Theoretical Medicine, Vol 25, 2004, pp 171-98.

Goodwin, Frederick K. and Jamison, Kay Redfield, Manic Depressive Illness: Bipolar Disorders and Recurrent Depression, Second Edition, Oxford University Press, New York, 2007.

Grisso, Thomas and Appelbaum, Paul S., "The MacArthur Treatment Competence Study III: Abilities of Patients to Consent to Psychiatric and Medical Treatments," Law and Hum Behav, Vol 149, No 19, 1995, pp 149-174.

Grisso, T, Appelbaum, PS, and Hill-Fotouhi, C., "The MacCAT-T: A Clinical Tool to Assess Patients' Capacities to Make Treatment Decisions," Psychiatr Serv, Vol 48, No 11, 1997, pp 1415-9.

Grisso, Thomas and Appelbaum, Paul S., Assessing Competence to Consent to Treatment: A Guide for Physicians and Other Health Professionals, New York, Oxford University Press, 1998.

Haney, C., Banks, W. C., \& Zimbardo, P. G. , “A Study of Prisoners and Guards in a Simulated Prison," Naval Research Review, Vol 30, 1973, pp 4-17.

Hyun, Insoo, "Waiver of Informed Consent, Cultural Sensitivity, and the Problem of Unjust Families and Traditions," The Hastings Center Report, Vol 32, No 5, SeptemberOctober, 2002, pp 14-22.

International Statistical Classification of Diseases and Related Health Problems (ICD10), https://www.cms.gov/Medicare/Coding/ICD10/Index.html, accessed October, 2015.

Janofsky, JS, McCarthy, RJ, and Folstein, MF, “The Hopkins Competency Assessment Test: A Brief Method for Evaluating Patients' Capacity to Give Informed Consent," Hosp Community Psychiatry, Vol 43, No 2, 1992, pp 132-6.

Kleespies, Philip M., Hughes, Douglas H. and Gallacher, Fiona P., "Suicide in the Medically and Terminally Ill: Psychological and Ethical Considerations," Journal of Clinical Psychology, Vol 56, No 9, 2000, pp 1153-71. 
Kutner, Jean S., Ruark, John E., and Raffin, Thomas A., "Defining Patient Competence for Medical Decision-making," Chest, Vol 100, No 5, November 1991, pp 1404-10.

Lee, Melinda A. and Ganzini, Linda, "Depression in the Elderly: Effect on Patient Attitudes Toward Life-Sustaining Therapy," J Am Geriatrics Society, Vol 40, No 10, October, 1992, pp 983-8.

Lee, Melinda and Ganzini, Linda, "The Effect of Recovery From Depression on Preferences for Life-Sustaining Therapy in Older Patients," Journal of Gerontology, Vol 49, No 1, 1994, pp M15-M21.

Lo, Bernard, Resolving Ethical Dilemmas: A Guide for Clinicians, Fifth Edition, Lippincott, Williams and Wilkins, New York, 2013, p 35.

Meisel, Alan, Roth, Loren H. and Lidz, Charles, "Toward a Model of the Legal Doctrine of Informed Consent," Am J Psychiatry, Vol 134, No 3, March 1977, pp 285-9.

Michelson, C., Mulvihill, M., Hsu, M.A., et.al., "Eliciting Medical Care Preferences from Nursing Home Residents," Gerontologist, Vol 31, 1991, pp 358-63.

Moffic, H.S. and Paykel, E.S., "Depression in Medical In-Patients," Brit J Psychiat, Vol 126, 1975, pp 346-53.

National Commission for the Protection of Human Subjects of Biomedical and Behavioral Research, (1979, section b (1), pp 282-30.

Nichita, Elena Carmen and Buckley, Peter F., "Informed Consent and Competency: Doctor's Dilemma on the Consultation Liaison Service," Psychiatry, March, 2007, pp 535 .

Pauker, SL and Cooper, AM, "Paradoxical Patient Reactions to Psychiatric Life Support: Clinical and Ethical Considerations," Am J Psychiatry, Vol 147, 1990, pp 488-91.

Peselow, E., Haelen, R., Stanley, B., et.al., "Affective Disorders and Capacity to Give Consent, " Paper presented at the American Psychiatric Association Meeting, Toronto, Canada, 1982.

President's Commission for the Study of Ethical Problems in Medicine and Biomedical and Behavioral Research, 1982, p 27.

Report and Recommendations of the National Bioethics Advisory Commission, Research Involving Persons with Mental Disorders That May Affect Decision Making Capacity, Vol. I, National Bioethics Advisory Commission, Rockville, MD, December 1998, p 58.

Roberts, Laura Weiss, "Informed Consent and the Capacity for Voluntarism," American Journal of Psychiatry, Vol 159, No 5, May 2002, pp 705-712. 
Roth, Loren H., Meisel, Alan and Lidz, Charles W., "Tests of competency to Consent to Treatment” Am J Psychiatry, Vol 134, No 3, March 1977, pp 279-84.

Rudnick, A, "Depression and Competence to Refuse Psychiatric Treatment," Journal of Medical Ethics, Vol 28, No 3, 2002, pp 151-5.

Schwartz, Harold I. and Blank, Karen, "Shifting Competency During Hospitalization: A Model for Informed Consent Decisions," Hospital and Community Psychiatry, Vol 37, 1986, pp 1256-60.

Segen's Medical Dictionary, Farlex, Inc, 2012, p 725.

Sherlock, Richard, "Competency to Consent to Medical Care: Toward a General View," General Hospital Psychiatry, Vol 6, 1984, pp 71-6.

Siegel, Karolynn, "Rational Suicide: Considerations for the Clinician," Psychiatric Quarterly, Vol 54, No 2, Summer 1982, pp 77-84.

Simon, Gregory E. and VonKorff, Michael, "Recognition, Management, and Outcomes of Depression in Primary Care," Arch Fam Med, Vol 4, Feb 1995, pp 99-105.

Sjostrand, Manne and Juth, Niklas, "Authenticity and Psychiatric Disorder: Does Autonomy of Personal Preferences Matter?” Medicine, Health Care and Philosophy, Vol 17, 2014, pp 115-122.

Stanley, Barbara, Stanley, Michael, Guido, Jeannine, et.al., "The Functional Competency of Elderly at Risk, The Gerontologist, Vol 28, 1988, pp Supplement 53-8.

Sullivan, Mark D. and Youngner, Stuart J., "Depression, Competence, and the Right to Refuse Lifesaving Medical Treatment," Am J Psychiatry, Vol 151, No 7, July 1994, pp 971-8.

Uhlmann, R.F., and Pearlman, R.A., "Perceived Quality of Life and Preferences for LifeSustaining Treatment in Older Adults, “ Arch Intern Med, Vol 151, 1991, pp 495-8.

Urmson, J.O., "Saints and Heroes," in Essays in Moral Philosophy, Melden. A., ed., Seattle: University of Washington Press, 1958, pp 193-199.

US President's Commission, Faden and Beauchamp, 1986, p 8.

WebPT, https://www.webpt.com/blog/post/history-icd-10, accessed February 19, 2017.

Weinstock, Robert, Copelan, Russell and Bagheri, Abbas, "Competence to Give Informed Consent for Medical Procedures," Bulletin of the American Academy of Psychiatry and the Law, Vol 12, No 2, 1984, pp 117-25. 
Welie, Sander P.K., "Criteria for Patient Decision-making (In)competence: A Review of and Commentary on Some Empirical Approaches," Medicine, Health Care and Philosophy, Vol 4 2001, pp 139-151.

World Health Organization, "History of the Development of the ICD,"://www.who.int/classifications/icd/en/HistoryOfICD.pdf, accessed February 18, 2017. 